the European Ceramic Society

Elsevier Editorial System(tm) for Journal of Manuscript Draft

Manuscript Number: JECS-D-17-01322R1

Title: Ordering of fluorite-type phases in erbium-doped oxyfluoride glass ceramics

Article Type: Full Length Article

Keywords: upconversion;

Ba4Yb3F17;

phase transition;

site-selective spectroscopy;

glass ceramics

Corresponding Author: Ms. Guna Krieke,

Corresponding Author's Institution: Institute of Solid State Physics

First Author: Guna Krieke

Order of Authors: Guna Krieke; Anatolijs Sarakovskis, Dr.Phys.; Maris Springis, Dr.Phys.

Abstract: In this study, novel transparent Er3+ doped glass ceramics were prepared from melt-quenched oxyfluoride glasses with general composition of Na2O-NaF-BaF2-YbF3-Al2O3-SiO2. The crystallization of fluorite (BaF2, $\mathrm{BaF} 2-\mathrm{YbF} 3, \mathrm{NaF}-\mathrm{BaF} 2-\mathrm{YbF} 3$ and $\mathrm{Na} 0.5-\mathrm{Xb} 0.5+\mathrm{xF} 2+2 \mathrm{x})$ and distorted fluorite (rhombohedral Ba4Yb3F17 and tetragonal NaF-BaF2-YbF3) phases was analysed in glass ceramics with different $\mathrm{BaF} 2$ and $\mathrm{YbF} 3$ ratio. The phase composition and microstructure were investigated by X-ray diffraction (XRD) and scanning electron microscopy (SEM). Intense red upconversion luminescence (UCL) was detected under near-infrared excitation resulting from three photon upconversion followed by cross-relaxation between Er3+ and $\mathrm{Yb} 3+$ ions.

The local environment of Er3+ ions in fluorite and distorted phases was analysed using site-selective spectroscopy. The Er3+ ions were found to act as nucleation centres in the glass ceramics containing BaF2. The phase transition from metastable fluorite to rhombohedrally and tetragonally distorted fluorite phases was detected using Er3+ ions as a probe. 
Dear reviewer, Thank you for your time and efforts spent during the revision of the manuscript.

We believe, that your recommendations will improve the quality of the manuscript. The changes made in the manuscript are highlighted.

The detailed response to the comments raised in your revision is given below.

Reviewer \#1: The authors systematically investigated the crystallization behaviors of BaF2$\mathrm{YbF} 3$ hybrid glasses. Using Er3+ dopants as probes, the local environments of Er3+ ions in crystallization phases were analysed with the help of size-selective spectroscopy. The results are important and well supported by experimental results. I recommend its publication after appropriate revisions.

(1) The detailed experimental procedure for preparing SEM sample should be provided.

More detailed experimental procedure for SEM characterization is now added in the section "Materials and methods".

(2) Figure 5. As a comparison, it is better to provide log-log plots for pure BaF2 embedded glass ceramics.

Unfortunately, due to low $\mathrm{Er}^{3+}$ content in the investigated glass ceramics no upconversion emission could be detected in the glass ceramics containing $\mathrm{BaF}_{2}\left(0 \% \mathrm{YbF}_{3}\right)$. This information is added in the text.

(3) It is better for the authors to provide Er3+ doping content dependent site-selective spectroscopy, especially for pure BaF2 embedded glass ceramics.

Thank you for this comment. We fully agree with the reviewer: it would indeed be very interesting to study the concentration dependence of site-selective spectroscopy in the glass ceramics. In our opinion it is beyond the scope of the current research. Nevertheless, we are considering to perform such experiments and afterwards report on them.

(4) Some related literatures concerning lanthanide-doped glass ceramics, such as J. Euro. Ceram. Soc., 2017, 37(13), 4083-4094, Anal. Chem., 2016, 88, 4099-4106, J. Euro. Ceram. Soc., 2015, 35, 3673-3679, ACS Appl. Mater. Interfaces, 2015, 7, 1948419493, J. Phys. Chem. Lett., 2015, 6, 2833-2840, J. Alloys Compd., 2015, 625, 149157, J. Mater. Sci. 2013, 48, 6262-6268 should be appropriately cited in the manuscript.

All of the recommended ([12], [19-21], [47-48] and [53]) and several additional articles ([2228]) are now cited in the manuscript. 


\title{
Ordering of fluorite-type phases in erbium-doped oxyfluoride glass ceramics
}

\author{
Guna Krieke*, Anatolijs Sarakovskis, Maris Springis \\ Institute of Solid State Physics, University of Latvia, 8 Kengaraga str., LV-1063, Riga, Latvia. \\ *Corresponding author, e-mail: guna.krieke@cfi.lu.lv
}

\begin{abstract}
In this study, novel transparent $\mathrm{Er}^{3+}$ doped glass ceramics were prepared from melt-quenched oxyfluoride glasses with general composition of $\mathrm{Na}_{2} \mathrm{O}-\mathrm{NaF}-\mathrm{BaF}_{2}-\mathrm{YbF}_{3}-\mathrm{Al}_{2} \mathrm{O}_{3}-\mathrm{SiO}_{2}$. The crystallization of fluorite $\left(\mathrm{BaF}_{2}, \mathrm{BaF}_{2}-\mathrm{YbF}_{3}, \mathrm{NaF}-\mathrm{BaF}_{2}-\mathrm{YbF}_{3}\right.$ and $\left.\mathrm{Na}_{0.5-\mathrm{x}} \mathrm{Yb}_{0.5+\mathrm{x}} \mathrm{F}_{2+2 \mathrm{x}}\right)$ and distorted fluorite (rhombohedral $\mathrm{Ba}_{4} \mathrm{Yb}_{3} \mathrm{~F}_{17}$ and tetragonal $\mathrm{NaF}-\mathrm{BaF}_{2}-\mathrm{YbF}_{3}$ ) phases was analysed in glass ceramics with different $\mathrm{BaF}_{2}$ and $\mathrm{YbF}_{3}$ ratio. The phase composition and microstructure were investigated by X-ray diffraction (XRD) and scanning electron microscopy (SEM). Intense red upconversion luminescence (UCL) was detected under nearinfrared excitation resulting from three photon upconversion followed by cross-relaxation between $\mathrm{Er}^{3+}$ and $\mathrm{Yb}^{3+}$ ions.

The local environment of $\mathrm{Er}^{3+}$ ions in fluorite and distorted phases was analysed using siteselective spectroscopy. The $\mathrm{Er}^{3+}$ ions were found to act as nucleation centres in the glass ceramics containing $\mathrm{BaF}_{2}$. The phase transition from metastable fluorite to rhombohedrally and tetragonally distorted fluorite phases was detected using $\mathrm{Er}^{3+}$ ions as a probe.
\end{abstract}

KEYWORDS: upconversion, $\mathrm{Ba}_{4} \mathrm{Yb}_{3} \mathrm{~F}_{17}$, phase transition, site-selective spectroscopy, glass ceramics

\section{Introduction}

Rare earth (RE) doped materials for up-conversion luminescence (UCL) have attracted attention due to various potential applications such as optical sensors and switches [1-3], optical memory devices [4,5], coatings for solar cells [6,7], three-dimensional displays [8,9], bioimaging and photodynamic therapy [10-12]. 
The highest efficiency of near-infrared to visible UCL has been detected in $\mathrm{Er}^{3+}$ doped materials due to multiple energy levels of $\mathrm{Er}^{3+}$ ions and similar energy gap between them [7]. However, suitable host with good RE solubility, low phonon energy and low local symmetry of RE ions is required.

Fluorides are known as excellent hosts for RE ions due to relatively low phonon energy possessing low rate of non-radiative relaxations, therefore enhancing the efficiency of UCL. $\mathrm{BaF}_{2}$ satisfies this criteria, having lower phonon energy $\left(346 \mathrm{~cm}^{-1}\right)$ than other alkaline earth fluorides [13]. Nevertheless, clustering of $\mathrm{Er}^{3+}$ ions, which leads to the enhanced rate of nonradiative relaxations, has been observed in $\mathrm{BaF}_{2}$ with $\mathrm{Er}^{3+}$ content as low as $0.05 \mathrm{~mol} \%$ [14]. This issue can be resolved by the introduction of other $\mathrm{RE}$ ions such as $\mathrm{La}^{3+}, \mathrm{Gd}^{3+}, \mathrm{Y}^{3+}$ and $\mathrm{Lu}^{3+}$ that act as spacers between $\mathrm{Er}^{3+}$ ions in RE clusters.

$\mathrm{BaF}_{2}$ forms unusually wide areas of fluorite type (face centred cubic) solid solutions with all $\mathrm{REF}_{3}$. In addition, two distorted fluorite-type phases have been detected in $\mathrm{BaF}_{2}-\mathrm{REF}_{3}$ binary systems: rhombohedral with idealized composition of $\mathrm{Ba}_{4} \mathrm{RE}_{3} \mathrm{~F}_{17}$ for $\mathrm{RE}=\mathrm{Sm}-\mathrm{Lu}$ and tetragonal high temperature phase $\mathrm{Ba}_{2} \mathrm{REF}_{7}$ for $\mathrm{RE}=\mathrm{Dy}-\mathrm{Lu}[15,16]$. The phase diagrams of $\mathrm{BaF}_{2}-\mathrm{REF}_{3}$ binary systems have been analysed in detail elsewhere $[15,17]$.

$\mathrm{Ba}^{2+}$ containing fluorite type phases have been extensively investigated in the nanocrystalline oxyfluoride glass ceramics. These hosts are suitable UCL materials for applications where transparency is required, combining the low phonon energy of the fluoride crystals with the high chemical and mechanical stability of oxide glasses [18]. The oxyfluoride glass ceramics have been extensively investigated for various application in photonics such as optical temperature sensing [19-21], light conversion [22,23], fibre lasers [24,25], x-ray imaging [26,27] and non-linear optics [28].

Efficient UCL has been observed in $\mathrm{RE}^{3+}$ doped glass ceramics containing $\mathrm{Ba}_{2} \mathrm{LaF}_{7}[29,30]$, $\mathrm{BaGdF}_{5}$ [31], $\mathrm{BaYF}_{5}$ [32], $\mathrm{BaYbF}_{5}$ [33], $\mathrm{BaLuF}_{5}$ [34] and $\mathrm{Ba}_{1-\mathrm{x}} \mathrm{Lu}_{\mathrm{x}} \mathrm{F}_{2+\mathrm{x}}$ [35]. The fluorite phases $\mathrm{Ba}_{2} \mathrm{LuF}_{7}$ and $\mathrm{BaREF}_{5}$ are non-stoichiometric solid solutions and should be expressed as $\mathrm{Ba}_{1-\mathrm{x}} \mathrm{RE}_{\mathrm{X}} \mathrm{F}_{2+\mathrm{x}}$ rather than individual compounds [18,36]. The chemical composition of these phases should be analysed carefully. According to the phase diagrams the $\mathrm{REF}_{3}$ content in the fluorite phases can reach up to $50 \mathrm{~mol} \%$ [15], however in systems far from thermodynamic 
equilibrium this region can be expanded even further by formation of metastable fluorite type phases that decompose after heat treatment $[37,38]$.

Recently we have developed new glass ceramics containing fluorite related phases. The formation of tetragonally and rhombohedrally distorted fluorite nanocrystals has been shown in $\mathrm{BaF}_{2}-\mathrm{YF}_{3}$ containing glass ceramics [39]. The crystallization of $\mathrm{Ba}_{4} \mathrm{Gd}_{3} \mathrm{~F}_{17}$ in oxyfluoride glass ceramics was investigated using $\mathrm{Er}^{3+}$ as a probe [40]. Phase transition from metastable cubic to rhombohedrally distorted fluorite type was detected and resulted in an enhancement of UCL.

In this research the phase formation and ordering of the fluorite-type structures are analysed in erbium doped $\mathrm{BaF}_{2}$ and $\mathrm{YbF}_{3}$ containing glass ceramics using $\mathrm{Er}^{3+}$ as a probe for the identification of the changes in the local structure and $\mathrm{Yb}^{3+}$ ions as a sensitizer for infrared to visible UCL. The origin of intense red UCL detected in the glass ceramics with $\mathrm{Yb}^{3+}$ containing fluorides is discussed.

\section{Materials and methods}

Precursor glasses with nominal composition of $15 \mathrm{Na}_{2} \mathrm{O}-3 \mathrm{NaF}-(14-\mathrm{x}) \mathrm{BaF}_{2}-\mathrm{XYbF}_{3}-6 \mathrm{Al}_{2} \mathrm{O}_{3}-$ $62 \mathrm{SiO}_{2}(\mathrm{x}=0,6-11$ and 14$)$ in $\mathrm{mol} \%$ doped with $0.1 \% \mathrm{ErF}_{3}$ were prepared from high purity raw materials. The batches of $9 \mathrm{~g}$ were melted in covered corundum crucibles at $1500^{\circ} \mathrm{C}$ for 30 minutes. The melts were casted in stainless steel mould. The chemical composition of the precursor glasses is summarized in Table 1. 
Table 1

Chemical composition of precursor glasses (in mol\%)

\begin{tabular}{lccccccc}
\hline Sample & $\mathrm{Na}_{2} \mathrm{O}$ & $\mathrm{NaF}$ & $\mathrm{BaF}_{2}$ & $\mathrm{YbF}_{3}$ & $\mathrm{Al}_{2} \mathrm{O}_{3}$ & $\mathrm{SiO}_{2}$ & $\mathrm{ErF}_{3}$ \\
\hline $0 \% \mathrm{YbF}_{3}$ & 15 & 3 & 14 & 0 & 6 & 62 & 0.1 \\
$6 \% \mathrm{YbF}_{3}$ & 15 & 3 & 8 & 6 & 6 & 62 & 0.1 \\
$7 \% \mathrm{YbF}_{3}$ & 15 & 3 & 7 & 7 & 6 & 62 & 0.1 \\
$8 \% \mathrm{YbF}_{3}$ & 15 & 3 & 6 & 8 & 6 & 62 & 0.1 \\
$9 \% \mathrm{YbF}_{3}$ & 15 & 3 & 5 & 9 & 6 & 62 & 0.1 \\
$10 \% \mathrm{YbF}_{3}$ & 15 & 3 & 4 & 10 & 6 & 62 & 0.1 \\
$11 \% \mathrm{YbF}_{3}$ & 15 & 3 & 3 & 11 & 6 & 62 & 0.1 \\
$14 \% \mathrm{YbF}_{3}$ & 15 & 3 & 0 & 14 & 6 & 62 & 0.1 \\
\hline
\end{tabular}

The glass ceramics were obtained after isothermal heat treatment of the precursor glasses at $500-700^{\circ} \mathrm{C}$ for $2 \mathrm{~h}$.

Polycrystalline $\mathrm{Ba}_{4} \mathrm{Yb}_{3} \mathrm{~F}_{17}$ was prepared using hydrothermal synthesis. Analytical grade raw materials were used. $1.5 \mathrm{mmol} \mathrm{Yb}^{3+}$ nitrate was prepared by dissolving $\mathrm{Yb}_{2} \mathrm{O}_{3}$ in concentrated $\mathrm{HNO}_{3}$. The excess $\mathrm{HNO}_{3}$ was removed by evaporation. $2 \mathrm{mmol} \mathrm{BaCl}_{2} \cdot 2 \mathrm{H}_{2} \mathrm{O}$ was added to the obtained nitrate and dissolved in $5 \mathrm{ml}$ of deionized water. Afterwards, $10 \mathrm{ml} 37.5 \mathrm{mmol} \mathrm{NH}_{4} \mathrm{~F}$ solution in deionized water was added under vigorous stirring. The solution was transferred to $25 \mathrm{ml}$ Teflon-lined autoclave and heated at $200^{\circ} \mathrm{C}$ for $24 \mathrm{~h}$ resulting in the formation of single phase rhombohedral $\mathrm{Ba}_{4} \mathrm{Yb}_{3} \mathrm{~F}_{17}$. After the reaction, the system was allowed to cool to room temperature naturally. The product was collected by filtration and dried in air.

The thermal properties of the glasses were characterized by differential thermal analysis (DTA) using differential thermal analyser Shimadzu Corp. DTG-60. Powdered samples were heated at $10 \mathrm{~K} / \mathrm{min}$ in $\mathrm{Ar}$ flow and $\mathrm{Al}_{2} \mathrm{O}_{3}$ was used as a reference.

X-ray diffraction data was obtained by PANalytical X'Pert Pro diffractometer using $\mathrm{Cu} \mathrm{K} \alpha$ tube operated at $45 \mathrm{kV}$ and $40 \mathrm{~mA}$. The structure refinement of tetragonal phase was performed by Fullprof [41] and indexed by TREOR [42]. 
The microstructure of the glass ceramics was characterized by scanning electron microscopy (SEM) using FE SEM, Tescan, Mira/LMU operated at $15 \mathrm{kV}$. The samples were fractured and mounted on sample stubs with conductive double coated carbon tape. No electroconductive coating was necessary due to good conductivity of the investigated glass ceramics. The micrographs were obtained by combining the signal from secondary electron and back scattered electron detectors.

Luminescence was excited by a wavelength tuneable pulsed solid state laser Ekspla NT342/3UV and temperature controlled continuous wave $(\mathrm{CW})$ laser diode $(\lambda=975 \mathrm{~nm})$. The emission signal was detected by Andor DU-401-BV CCD camera coupled to Andor SR-303iB spectrometer. Luminescence decay was measured using a photomultiplier tube and digital oscilloscope Tektronix TDS 684A. Low temperature measurements were performed using Advanced Research Systems DE202 N cold finger type He cryostat.

\section{Results and discussion}

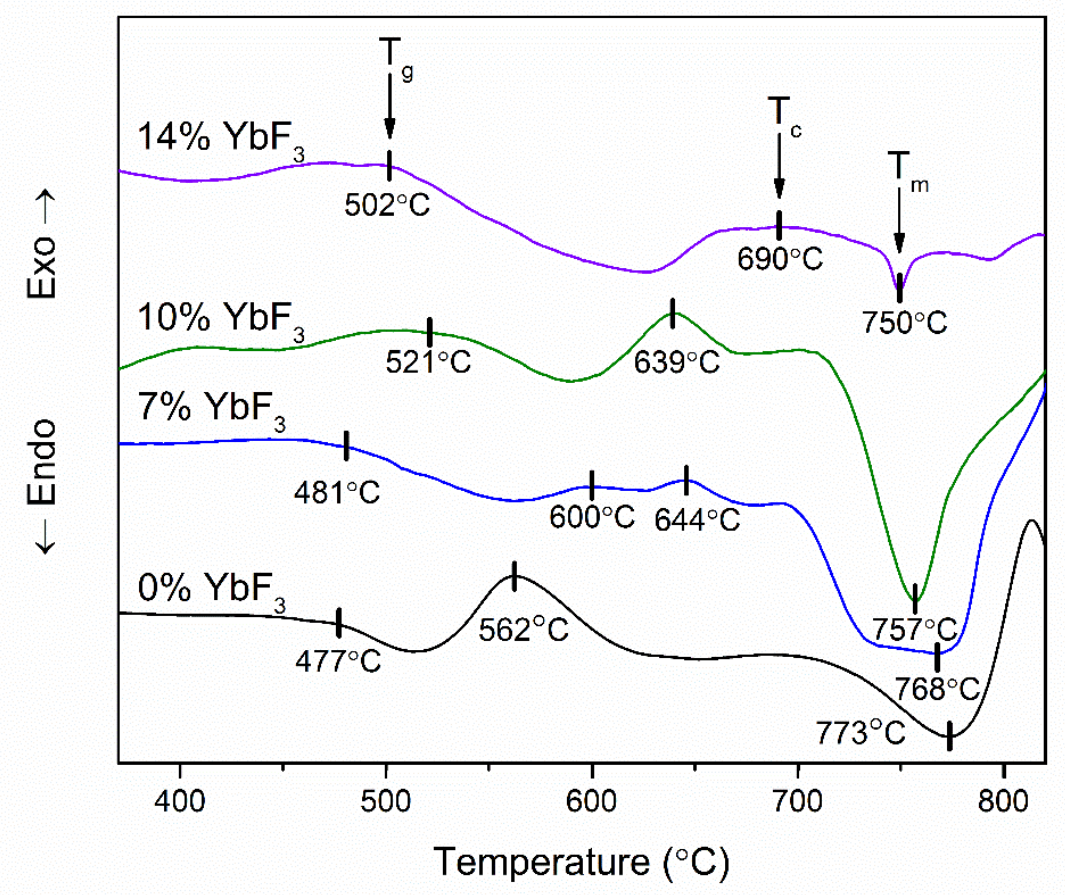

Fig. 1. DTA curves of the precursor glasses with $0,7,10$ and $14 \% \mathrm{YbF}_{3}$ 


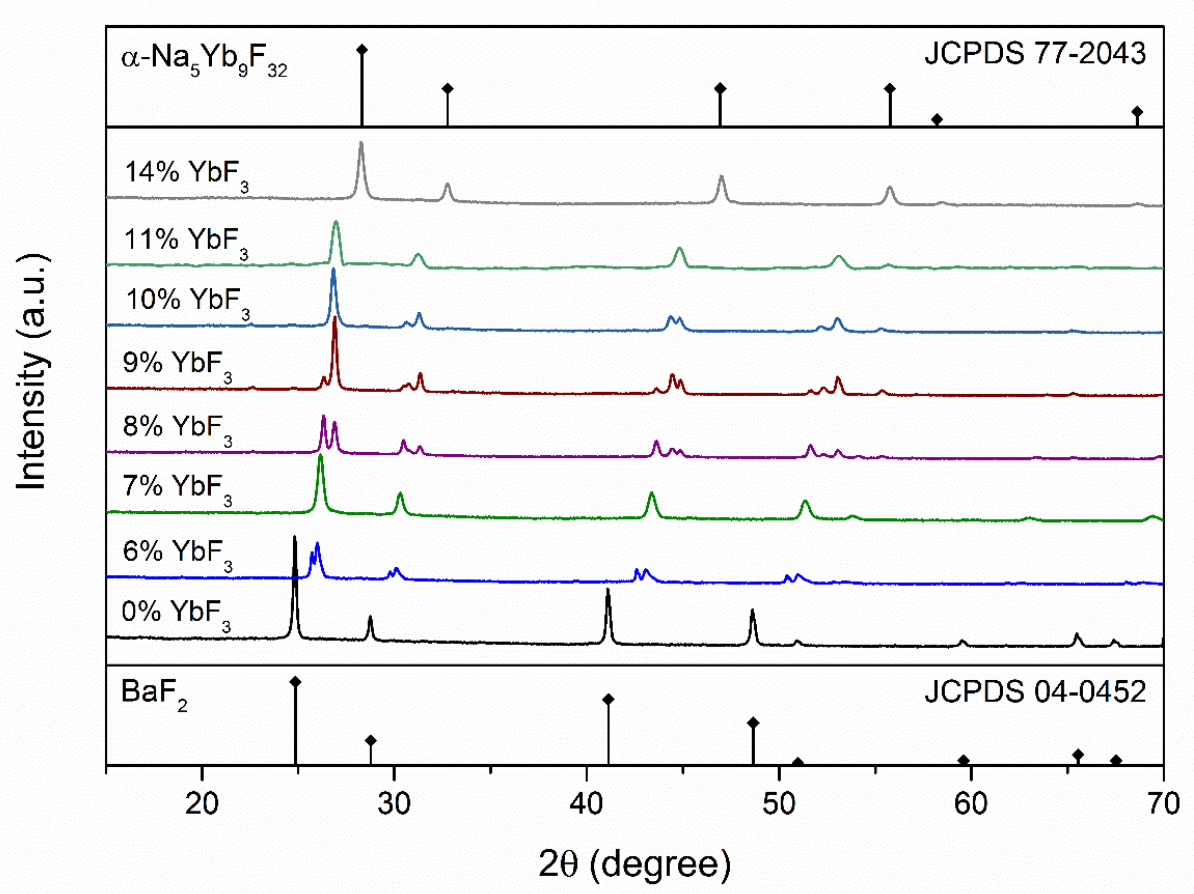

Fig. 2. XRD patterns of the glass ceramics heat treated at $650^{\circ} \mathrm{C}$ for $2 \mathrm{~h}$. transition temperature $\mathrm{T}_{\mathrm{g}}$ of these precursors is located at approximately $500^{\circ} \mathrm{C}$ and decreases slightly with the replacement of $\mathrm{BaF}_{2}$ by $\mathrm{YbF}_{3}$. This could be explained by lower stability of $\mathrm{YbF}_{3}$ in the melt leading to decrease of fluorine content in the precursor glass or the decrease of the content of glass modifiers in the glass due to partial crystallization of the glass during the cooling of the melt (see Fig. 3). For the glass ceramics with $0 \% \mathrm{YbF}_{3}$ single exothermic effect $\left(\mathrm{T}_{\mathrm{c}}\right)$ with temperature maximum at $562^{\circ} \mathrm{C}$ associated with the crystallization of $\mathrm{BaF}_{2}$ is observed. The introduction of $\mathrm{YbF}_{3}$ results in changes in the crystallization processes. For the glass ceramics with 10 and $14 \% \mathrm{YbF}_{3}$ broad exothermic effects associated with the formation of fluoride phases are observed suggesting gradual crystallization. For the glass ceramics with $7 \% \mathrm{YbF}_{3}$ two distinct exothermic effects are observed indicating the crystallization of several fluoride phases. Finally, an endothermic effect $T_{m}$ associated with the melting of the glass matrix is observed for all the investigated glasses and is located at approximately $750-780^{\circ} \mathrm{C}$.

All the precursor glasses were heat treated at $650^{\circ} \mathrm{C}$ for $2 \mathrm{~h}$ and the phase composition of the obtained glass ceramics was analysed by XRD (see Fig. 2). 
In the glass ceramics with $0 \% \mathrm{YbF}_{3}$ fluorite type crystals with lattice parameter $\mathrm{a}=6.2064 \pm 0.0004 \AA$ are formed and are in a good agreement with cubic $\mathrm{BaF}_{2}$.

According to the phase diagram of $\mathrm{BaF}_{2}-\mathrm{YbF}_{3}$ binary system, the replacement of $\mathrm{BaF}_{2}$ by $\mathrm{YbF}_{3}$ should result in the formation of non-stoichiometric fluorite phases, fluorite related rhombohedral $\mathrm{Ba}_{4} \mathrm{Yb}_{3} \mathrm{~F}_{17}$ and tetragonal $\mathrm{Ba}_{2} \mathrm{YbF}_{7}$ as well as monoclinic or orthorhombic $\mathrm{BaYb}_{2} \mathrm{~F}_{8}$ and orthorhombic or hexagonal $\mathrm{YbF}_{3}[15,17]$, however in all the investigated glass ceramics only fluorite and fluorite related phases were formed.

The replacement of $\mathrm{BaF}_{2}$ by $\mathrm{YbF}_{3}$ results in the decrease of the interplanar distances of the fluorite lattice. In the glass ceramics with $6 \% \mathrm{YbF}_{3}$ two crystalline phases are formed. One is assumed to be fluorite type $\mathrm{BaF}_{2}-\mathrm{YbF}_{3}$ solid solution. The other can be precipitated in the glass ceramics with $7 \% \mathrm{YbF}_{3}$ as a single crystalline phase. The interplanar distances of this compound are close to cubic $\mathrm{Ba}_{4} \mathrm{Yb}_{3} \mathrm{~F}_{17}$ [43] and it is structurally similar to its ordered phase rhombohedral $\mathrm{Ba}_{4} \mathrm{Yb}_{3} \mathrm{~F}_{17}$ (see Fig. 3 a). In the glass ceramics with 8-10\% $\mathrm{YbF}_{3}$ another fluorite related compound with tetragonal distortion is formed.

No distortion of fluorite lattice can be observed in the glass ceramics with $11 \%$ and $14 \% \mathrm{YbF}_{3}$, therefore the formation of $\mathrm{NaF}-\mathrm{BaF}_{2}-\mathrm{YbF}_{3}$ and $\mathrm{Na}_{0.5-\mathrm{x}} \mathrm{Yb}_{0.5+\mathrm{x}} \mathrm{F}_{2+2 \mathrm{x}}$ solid solutions are assumed. The lattice parameter of the latter compound $\left(14 \% \mathrm{YbF}_{3}\right) \mathrm{a}=5.4644 \pm 0.0004 \AA$ is close to $\mathrm{Na}_{5} \mathrm{Yb}_{9} \mathrm{~F}_{32}(\mathrm{a}=5.4710 \AA)-\mathrm{a}$ fluorite-type solid solution with upper $\mathrm{YbF}_{3}$ content. The expansion of the lattice due to introduction of larger ions $\left(\mathrm{Er}^{3+}\right)$ in the crystalline structure should be rather insignificant due to low $\mathrm{ErF}_{3}$ content in the precursor glass, therefore the deviation of the lattice parameter should be caused by the different $\mathrm{NaF} / \mathrm{YbF}_{3}$ ratio. The chemical composition of nanocrystals was estimated to be $\mathrm{Na}_{0.41} \mathrm{Yb}_{0.59} \mathrm{~F}_{2.18}$ using empirical equations from Ref [44].

The phase formation of fluorite-related phases in the glass ceramics with $7 \%$ and $10 \% \mathrm{YbF}_{3}$ was investigated in detail and the XRD results are shown in Fig. 3. 

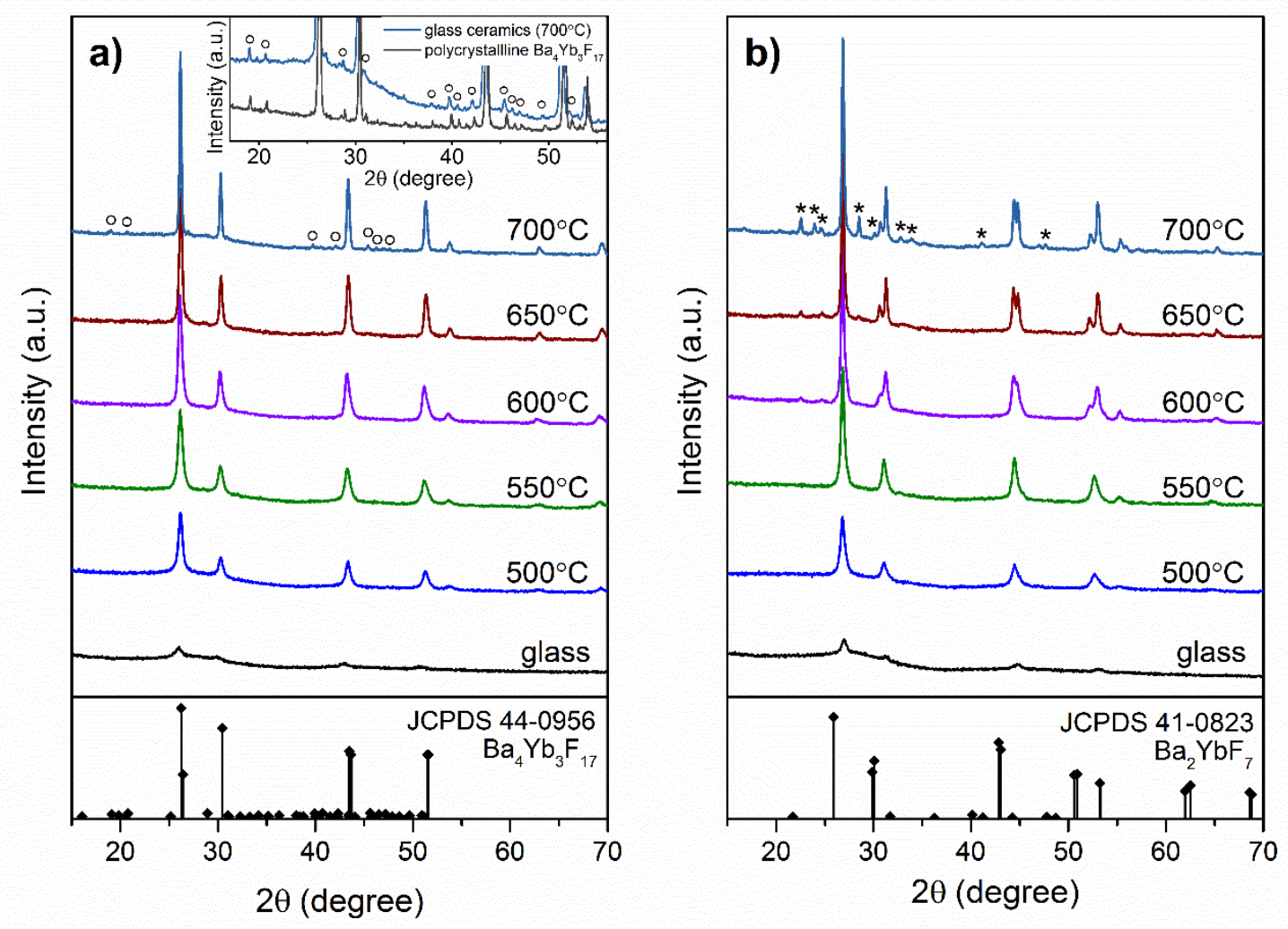

Fig. 3. XRD patterns of the precursor glass and glass ceramics with a) $7 \% \mathrm{YbF}_{3}$ (superstructure peaks are marked with o) and b) $10 \% \mathrm{YbF}_{3}$ (impurity phase is marked by *).

Inset: the comparison of superstructure peaks of the glass ceramics and polycrystalline

$$
\mathrm{Ba}_{4} \mathrm{Yb}_{3} \mathrm{~F}_{17} \text {. }
$$

No intense diffraction peaks were detected for the precursor glasses, however broad, low intensity peaks corresponding to the most intense peaks of fluorite-type lattices suggest partial spontaneous crystallization of the fluorite phases during the cooling of the melt. In the glass ceramics with $7 \% \mathrm{YbF}_{3}$ an increase of the diffraction intensity and the narrowing of the XRD peaks after the heat treatment is observed, suggesting the growth of the nanocrystals. Despite the two exothermic effects detected by DTA (See Fig. 1), no significant changes in the crystalline structure for the glass ceramics heat treated at $500-700^{\circ} \mathrm{C}$ have been observed. Several weak superstructure peaks in the glass ceramics heat treated at $700^{\circ} \mathrm{C}$ for $2 \mathrm{~h}$ (see inset of Fig. 3 a) indicate the rhombohedral distortion of the fluorite phase corresponding to a compound with idealized composition of $\mathrm{Ba}_{4} \mathrm{Yb}_{3} \mathrm{~F}_{17}$. The results suggest an ordering of metastable cubic and formation of ordered rhombohedral phase, however relatively broad 
peaks of the nanocrystals and weak superstructure reflections of the ordered phase prevent the precise identification of the phase transition using XRD.

Similarly, in the glass ceramics with $10 \% \mathrm{YbF}_{3}$ (Fig. 3 b) at low temperature fluorite nanocrystals are formed, however after the heat treatment at $600^{\circ} \mathrm{C}$ splitting of $200(31.122 \theta)$

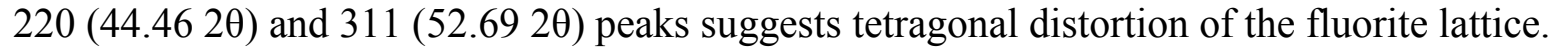

Tetragonally distorted fluorite related high-temperature compound with general composition of $\mathrm{Ba}_{2} \mathrm{YbF}_{7}$ has been observed in $\mathrm{BaF}_{2}-\mathrm{YbF}_{3}$ binary system [16] and the line pattern of this phase is shown in Fig. 3 b, however considerable peak shifts are detected indicating considerably larger unit cell of the $\mathrm{Ba}_{2} \mathrm{YbF}_{7}$ in comparison to the tetragonal nanocrystals the investigated glass ceramics.

The tetragonal indexing of the distorted fluorite phase matches space group P4/mmm (No. 123) with the cell parameters $a=b=4.0392 \AA, c=5.8305 \AA$ and tetragonal subcell is elongated along $\mathrm{c}$ axis in comparison to the fluorite phase. The crystallization of isostructural tetragonally distorted fluorite type phase identified as $\mathrm{NaF}-\mathrm{BaF}_{2}-\mathrm{YF}_{3}$ solid solution has been detected in $\mathrm{YF}_{3}$ containing glass ceramics [39]. We assume the formation of similar NaF$\mathrm{BaF}_{2}-\mathrm{YbF}_{3}$ solid solution in the investigated glass ceramics. Unfortunately, the phase equilibrium of $\mathrm{NaF}-\mathrm{BaF}_{2}-\mathrm{YbF}_{3}$ system has not been investigated in details and our attempts to prepare this compound using solid state synthesis were not successful.

Further increase of the temperature of the heat treatment promotes growth of the tetragonal nanocrystals in the glass ceramics with $10 \% \mathrm{YbF}_{3}$. In addition, an unidentified crystalline phase (marked with * in Fig. $3 \mathrm{~b}$ ) is formed after the heat treatment at $700^{\circ} \mathrm{C}$ for $2 \mathrm{~h}$.

The crystalline phases present in the glass ceramics after heat treatment at $650^{\circ} \mathrm{C}$ for $2 \mathrm{~h}$ are summarized in Table 2. 
Table 2

\begin{tabular}{lc}
\hline Sample & Crystalline phase \\
\hline $0 \% \mathrm{YbF}_{3}$ & cubic $\mathrm{BaF}_{2}$ \\
$6 \% \mathrm{YbF}_{3}$ & cubic $\mathrm{BaF}_{2}-\mathrm{YbF}_{3}$ solid solution + rhombohedral $\mathrm{Ba}_{4} \mathrm{Yb}_{3} \mathrm{~F}_{17}$ \\
$7 \% \mathrm{YbF}_{3}$ & rhombohedral $\mathrm{Ba}_{4} \mathrm{Yb}_{3} \mathrm{~F}_{17}$ \\
$8 \% \mathrm{YbF}_{3}$ & rhombohedral $\mathrm{Ba}_{4} \mathrm{Yb}_{3} \mathrm{~F}_{17}+$ tetragonal NaF- $\mathrm{BaF}_{2}-\mathrm{YbF}_{3}$ \\
$9 \% \mathrm{YbF}_{3}$ & rhombohedral $\mathrm{Ba}_{4} \mathrm{Yb}_{3} \mathrm{~F}_{17}+$ tetragonal NaF- $\mathrm{BaF}_{2}-\mathrm{YbF}_{3}$ \\
$10 \% \mathrm{YbF}_{3}$ & tetragonal NaF-BaF$-\mathrm{YbF}_{3}$ \\
$11 \% \mathrm{YbF}_{3}$ & cubic NaF-BaF$-\mathrm{YbF}_{3}$ solid solution \\
$14 \% \mathrm{YbF}_{3}$ & cubic $\mathrm{Na}_{0.41} \mathrm{Yb}_{0.59} \mathrm{~F}_{2.18}$ \\
\hline
\end{tabular}

The glass ceramics heat treated up to $650^{\circ} \mathrm{C}$ for $2 \mathrm{~h}$ remain transparent, however higher temperature promotes rapid growth of the nanocrystals with distinct morphology.
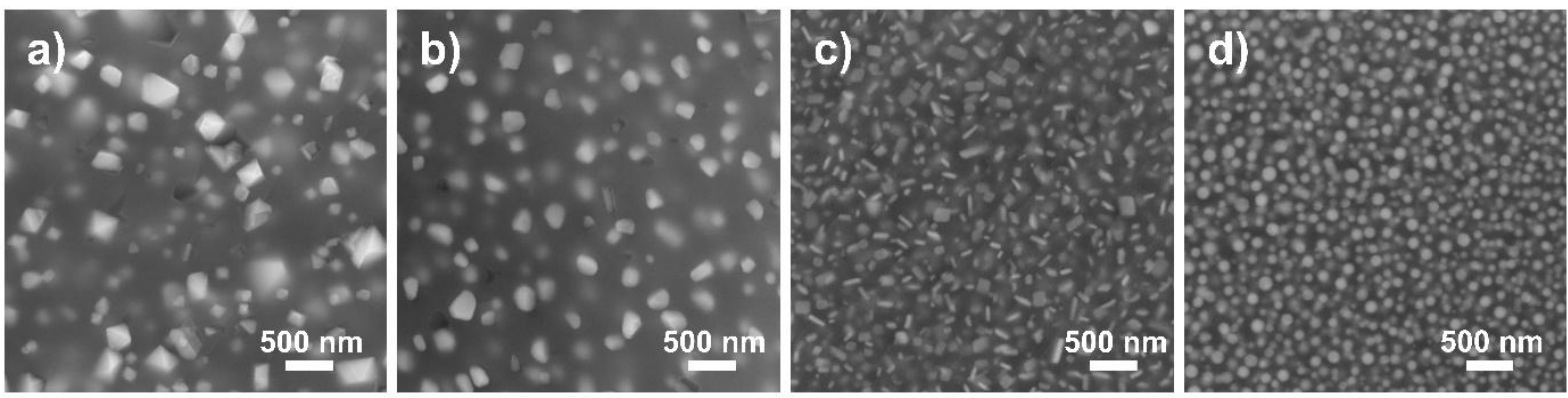

Fig. 4. SEM micrographs of the glass ceramics with a) $0 \%$, b) $7 \%$, c) $10 \%$, and d) $14 \% \mathrm{YbF}_{3}$ heat treated at $700^{\circ} \mathrm{C}$ for $2 \mathrm{~h}$.

The SEM micrographs of the glass ceramics with different $\mathrm{YbF}_{3}$ content are shown in Fig. 4. The lighter sections represent crystalline regions enriched in heavy element ions such as $\mathrm{Ba}^{2+}$ and $\mathrm{Yb}^{3+}$, and the darker sections represent the glass matrix mostly containing lighter ions. In $\mathrm{BaF}_{2}$ containing glass ceramics $\left(0 \% \mathrm{YbF}_{3}\right)$ randomly oriented octahedral crystals with a broad size distribution are formed. Homogenous distribution of smaller nanocrystals is detected in $\mathrm{Yb}^{3+}$ containing glass ceramics suggesting lower crystal growth velocity. Blocky and tabular crystals are formed in the glass ceramics with $7 \% \mathrm{YbF}_{3}$ (rhombohedral $\mathrm{Ba}_{4} \mathrm{Yb}_{3} \mathrm{~F}_{17}$ ) and $10 \%$ $\mathrm{YbF}_{3}$ (tetragonal $\mathrm{NaF}-\mathrm{BaF}_{2}-\mathrm{YbF}_{3}$ ) respectively. Similar morphology has been observed in $\mathrm{Y}^{3+}$ 
containing glass ceramics [39]. For the glass ceramics with $14 \% \mathrm{YbF}_{3}\left(\mathrm{Na}_{0.41} \mathrm{Yb}_{0.59} \mathrm{~F}_{2.18}\right.$ solid solution) spherical particles are formed. This morphology is characteristic to other oxyfluoride glass ceramics, in which the growth of the nanocrystals is limited by a diffusion barrier formed around the crystallites [45-48]. In the investigated glass ceramics, the crystallization of $\mathrm{Na}_{0.41} \mathrm{Yb}_{0.59} \mathrm{~F}_{2.18}$ reduces the content of glass modifiers $\left(\mathrm{Na}^{+}\right.$and $\left.\mathrm{RE}^{3+}\right)$ in the base glass, therefore increasing the viscosity of the glass matrix surrounding the crystals and preventing their further growth.

In all $\mathrm{Yb}^{3+}$ containing glass ceramics intense red UCL was observed in comparison to glass ceramics with $0 \% \mathrm{YbF}_{3}$ where no UCL could be detected. The UCL spectra of the glass ceramics with the distorted fluorite-type (7\% and $\left.10 \% \mathrm{YbF}_{3}\right)$ and $\mathrm{Na}_{0.41} \mathrm{Yb}_{0.59} \mathrm{~F}_{2.18}\left(14 \% \mathrm{YbF}_{3}\right)$ nanocrystals are shown in Fig. 5.

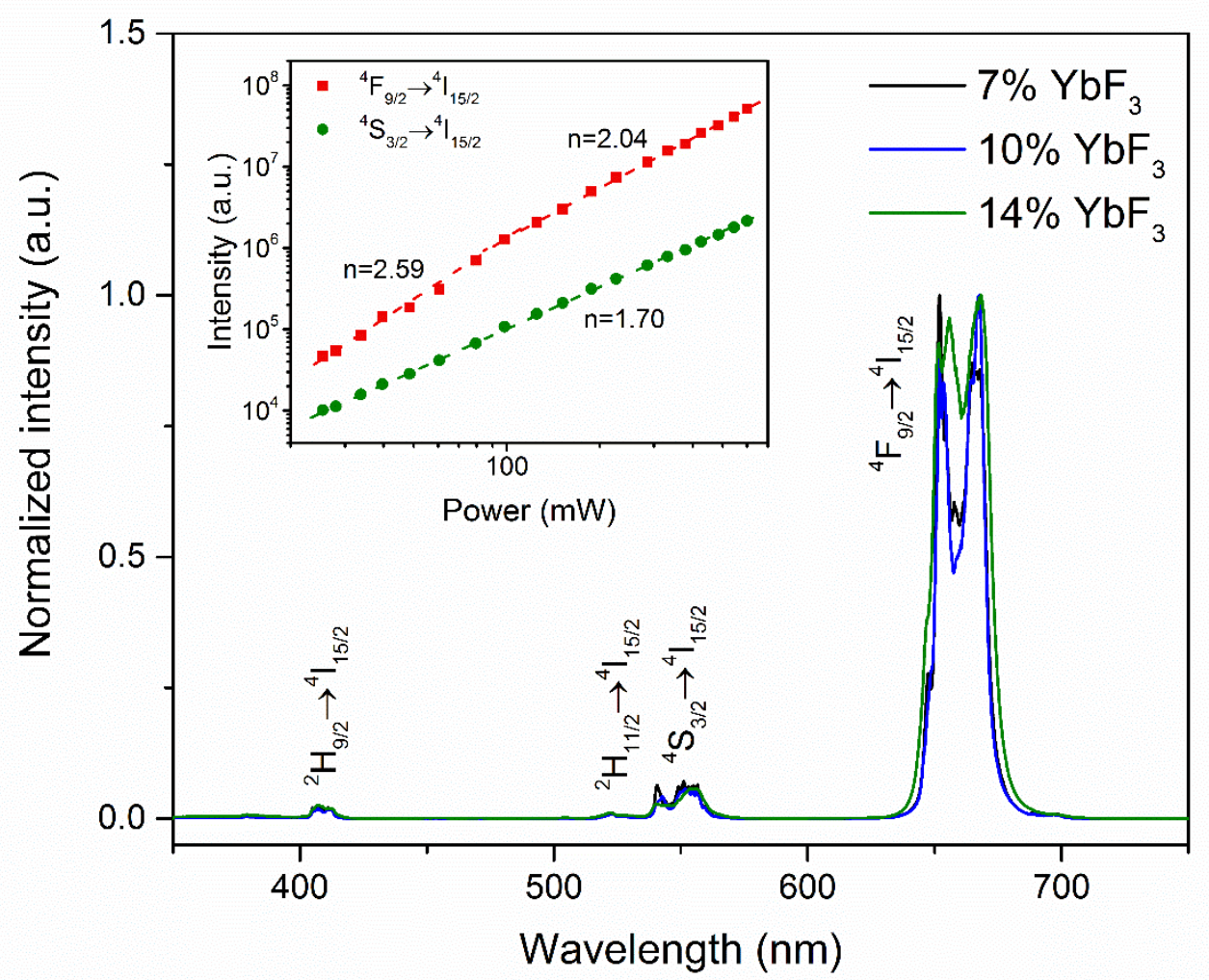

Fig. 5. UCL spectra of the glass ceramics with 7, 10 and $14 \% \mathrm{YbF}_{3}$ heat treated at $650^{\circ} \mathrm{C}$ for $2 \mathrm{~h}$ under $973 \mathrm{~nm}$ excitation. Inset: power dependence of UCL intensity of ${ }^{4} \mathrm{~F}_{9 / 2} \rightarrow{ }^{4} \mathrm{I}_{15 / 2}$ (red) and ${ }^{4} \mathrm{~S}_{3 / 2} \rightarrow{ }^{4} \mathrm{I}_{15 / 2}$ (green) emission in the glass ceramics with $7 \% \mathrm{YbF}_{3}$. 
The most intense emission band in all $\mathrm{Yb}^{3+}$ containing glass ceramics centred at $655 \mathrm{~nm}$ corresponds to ${ }^{4} \mathrm{~F}_{9 / 2} \rightarrow{ }^{4} \mathrm{I}_{15 / 2}$ transition of $\mathrm{Er}^{3+}$ ions. Several lower intensity UCL bands can be assigned to ${ }^{2} \mathrm{H}_{9 / 2} \rightarrow{ }^{4} \mathrm{I}_{15 / 2}(410 \mathrm{~nm}),{ }^{2} \mathrm{H}_{11 / 2} \rightarrow{ }^{4} \mathrm{I}_{15 / 2}(520 \mathrm{~nm})$ and ${ }^{4} \mathrm{~S}_{3 / 2} \rightarrow{ }^{4} \mathrm{I}_{15 / 2}(550 \mathrm{~nm})$ transitions characteristic to $\mathrm{Er}^{3+}$.

In $\mathrm{Er}^{3+}$ doped fluorides at low $\mathrm{Er}^{3+}$ content green emission arising from two photon UCL process is usually dominant $[49,50]$, whereas in materials with high $\mathrm{Yb}^{3+}$ content intense red emission is usually observed [51-53]. In similar $\mathrm{Yb}^{3+}$ containing glass ceramics it is assumed to be due to non-radiative multiphonon relaxation from ${ }^{4} \mathrm{~S}_{3 / 2}$ to ${ }^{4} \mathrm{~F}_{9 / 2}$ directly populating the red emitting state or from ${ }^{4} \mathrm{I}_{11 / 2}$ to ${ }^{4} \mathrm{I}_{13 / 2}$ followed by energy transfer from ${ }^{4} \mathrm{I}_{13 / 2}$ to ${ }^{4} \mathrm{~F}_{9 / 2}$, as well as several cross-relaxation processes between $\mathrm{Er}^{3+}$ ions [54-56]. The multiphonon relaxation from ${ }^{4} S_{3 / 2}$ and ${ }^{4} I_{11 / 2}$ to lower emitting states are not efficient in low-phonon hosts such as fluorides and the cross-relaxation processes between $\mathrm{Er}^{3+}$ ions are insignificant in the investigated glass ceramics due to low $\mathrm{Er}^{3+}$ content, therefore an alternative pathway for the population of red-emitting state can be expected.

For the UCL processes, the emission intensity is proportional to the $\mathrm{n}$-th power of excitation power, where $\mathrm{n}$ is the number photons required to excite the emitting states in case of small upconversion rates and less than that in actual UCL systems [57]. In order to understand the UCL mechanism in the investigated glass ceramics, the pumping power dependence of UCL intensity of green and red emission was investigated and represented for the glass ceramics with $7 \% \mathrm{YbF}_{3}$ in inset of Fig. 5.

The slopes of the $\log -\log$ pump power dependences of the green $\left({ }^{4} \mathrm{~S}_{3 / 2} \rightarrow{ }^{4} \mathrm{I}_{15 / 2}\right)$ and red $\left({ }^{4} \mathrm{~F}_{9 / 2} \rightarrow{ }^{4} \mathrm{I}_{15 / 2}\right)$ emissions show considerable differences. For the green emission the slope $\mathrm{n}=1.7$ is close to 2 , indicating two photon UCL, however for the red emission $n=2.59$ for low power region suggests that three photon UCL process is involved in the population of the red emitting state. 

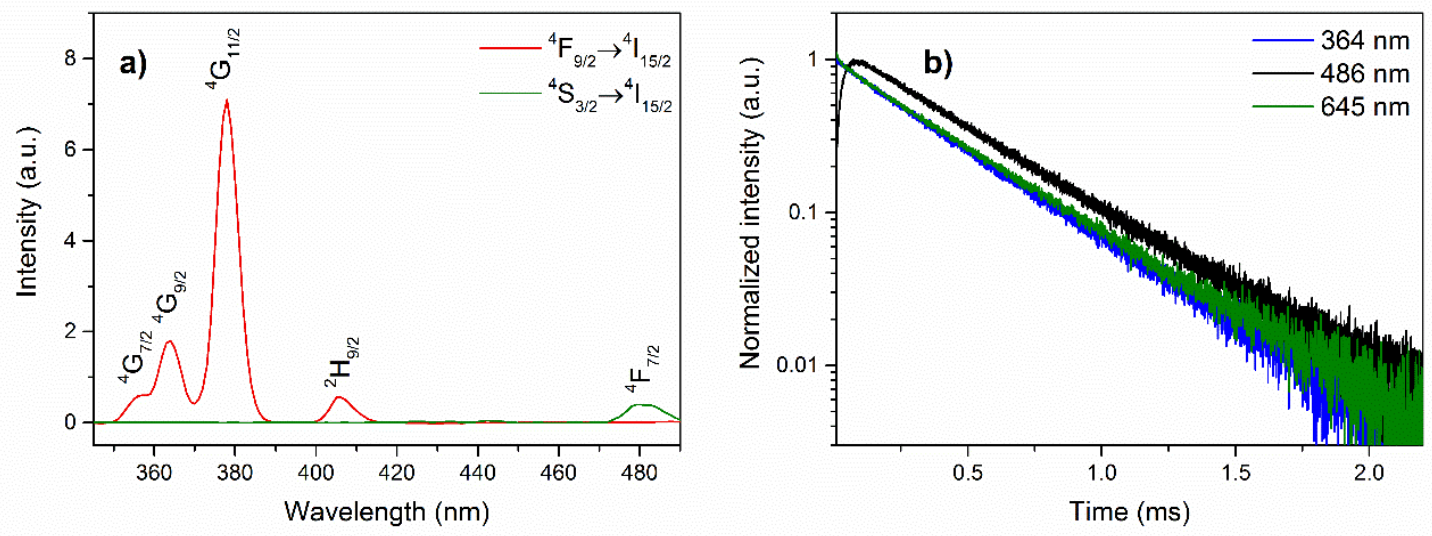

Fig. 6. a) Photoluminescence excitation spectra for ${ }^{4} \mathrm{~S}_{3 / 2} \rightarrow{ }^{4} \mathrm{I}_{15 / 2}$ (green) and ${ }^{4} \mathrm{~F}_{9 / 2} \rightarrow{ }^{4} \mathrm{I}_{15 / 2}$ (red) emission and b) luminescence decay of ${ }^{4} \mathrm{~F}_{9 / 2} \rightarrow{ }^{4} \mathrm{I}_{15 / 2}$ emission excited at 364, 486 and $645 \mathrm{~nm}$ of the glass ceramics with $7 \% \mathrm{YbF}_{3}$ heat treated at $650^{\circ} \mathrm{C}$ for $2 \mathrm{~h}$.

The dominant cross-relaxation pathway in the investigated glass ceramics is revealed in the photoluminescence excitation spectra shown in Fig. 6. The green emission $\left({ }^{4} S_{3 / 2} \rightarrow{ }^{4} I_{15 / 2}\right.$ transition) is observed upon excitation at $480 \mathrm{~nm}\left({ }^{4} \mathrm{I}_{15 / 2} \rightarrow{ }^{4} \mathrm{~F}_{7 / 2}\right)$, but the emission intensity is insignificant for shorter excitation wavelengths (below $450 \mathrm{~nm}$ ). In this spectral region only red luminescence can be excited efficiently. Several bands centred at 358, 364, 378 and 406 nm assigned to ${ }^{4} \mathrm{I}_{15 / 2} \rightarrow{ }^{4} \mathrm{G}_{7 / 2},{ }^{4} \mathrm{I}_{15 / 2} \rightarrow{ }^{4} \mathrm{G}_{9 / 2},{ }^{4} \mathrm{I}_{15 / 2} \rightarrow{ }^{4} \mathrm{G}_{11 / 2}$ and ${ }^{4} \mathrm{I}_{15 / 2} \rightarrow{ }^{2} \mathrm{H}_{9 / 2}$ transitions respectively were detected suggesting non-radiative decay pathway from these states to ${ }^{4} \mathrm{~F}_{9 / 2}$ that bypasses the green emitting state. This assumption is confirmed by the luminescence decay trends of the red emission shown in Fig. 6 b) in the glass ceramics with $7 \% \mathrm{YbF}_{3}$ after excitation at $364 \mathrm{~nm}$ $\left({ }^{4} \mathrm{I}_{15 / 2} \rightarrow{ }^{4} \mathrm{G}_{9 / 2}\right), 486 \mathrm{~nm}\left({ }^{4} \mathrm{I}_{15 / 2} \rightarrow{ }^{4} \mathrm{~F}_{7 / 2}\right)$ and $645 \mathrm{~nm}$ directly populating ${ }^{4} \mathrm{~F}_{9 / 2}$ emitting state. Single exponential decay is observed for the excitation at 364 and $645 \mathrm{~nm}$. The non-exponential behaviour of the red luminescence after $486 \mathrm{~nm}$ excitation suggests that the energy transfer mechanism is involved. Rapid non-radiative decay ${ }^{4} \mathrm{G}_{7 / 2} \rightarrow{ }^{4} \mathrm{G}_{9 / 2} \rightarrow{ }^{4} \mathrm{G}_{11 / 2} \rightarrow{ }^{2} \mathrm{H}_{9 / 2}$ is expected in these materials and the ${ }^{2} \mathrm{~F}_{7 / 2} \rightarrow{ }^{2} \mathrm{~F}_{5 / 2}$ transition of $\mathrm{Yb}^{3+}$ ions is resonant with ${ }^{2} \mathrm{H}_{9 / 2} \rightarrow{ }^{4} \mathrm{~F}_{9 / 2}$ suggesting cross-relaxation process $\left({ }^{2} \mathrm{H}_{9 / 2},{ }^{4} \mathrm{~F}_{7 / 2} \rightarrow{ }^{4} \mathrm{~F}_{9 / 2},{ }^{4} \mathrm{~F}_{5 / 2}\right)$. The results confirm that the population of ${ }^{4} \mathrm{~F}_{9 / 2}$ occurs due to cross-relaxation from ${ }^{2} \mathrm{H}_{9 / 2}$ to ${ }^{4} \mathrm{~F}_{9 / 2}$ that bypasses the intermediate states.

The proposed UCL mechanism is summarized in Fig. 7. 


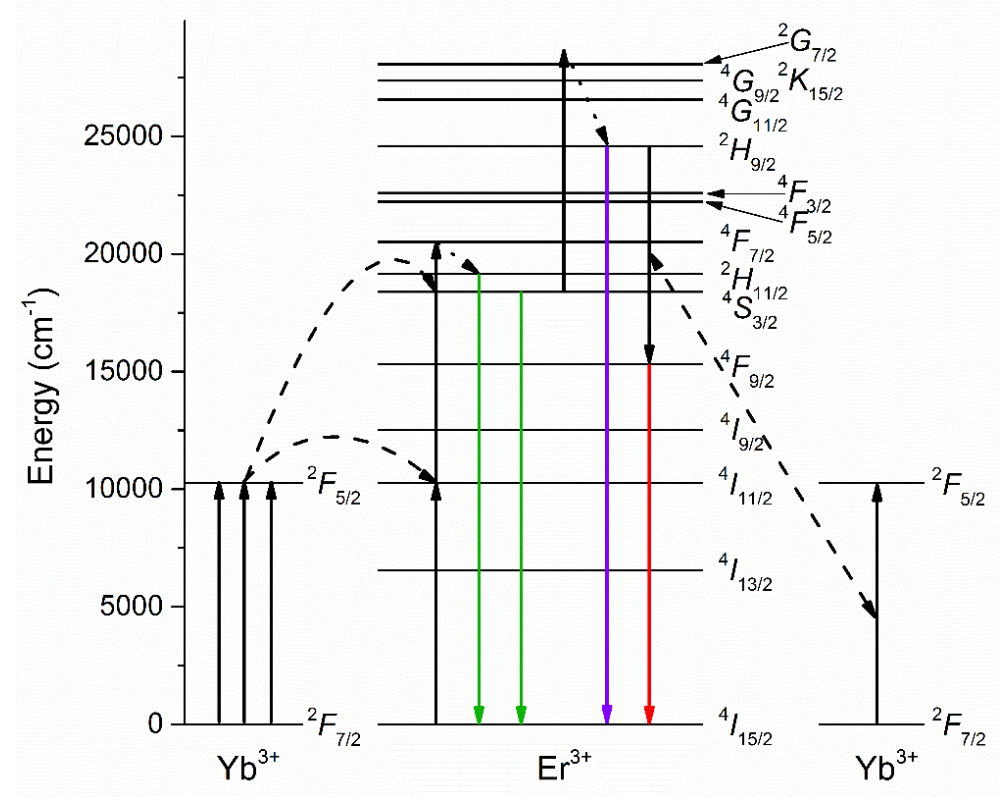

Fig. 7. Partial energy level scheme of $\mathrm{Er}^{3+}$ and $\mathrm{Yb}^{3+}$ ions with possible UCL and crossrelaxation mechanisms.

Under near-infrared excitation $\mathrm{Yb}^{3+}$ ions in the investigated glass ceramics are promoted to ${ }^{2} \mathrm{~F}_{5 / 2}$ through ground-state absorption. Resonant energy transfer to $\mathrm{Er}^{3+}$ populates ${ }^{4} \mathrm{I}_{11 / 2}$ and ${ }^{4} \mathrm{~F}_{7 / 2}$ levels of $\mathrm{Er}^{3+}$ ions. The rapid non-radiative decay from ${ }^{4} \mathrm{~F}_{7 / 2}$ to ${ }^{2} \mathrm{H}_{11 / 2}$ and ${ }^{4} \mathrm{~S}_{3 / 2}$ populates the emitting states resulting in the green emission. The relatively long lifetime of these emitting states also enables further excitation of $\mathrm{Er}^{3+}$ ions to ${ }^{2} \mathrm{G}_{7 / 2}$, from which non-radiative multiphonon relaxation populates ${ }^{2} \mathrm{H}_{9 / 2}$. Only insignificant fraction of $\mathrm{Er}^{3+}$ ions decay from this state radiatively (see Fig. 5). Due to high $\mathrm{Yb}^{3+}$ ions content in the crystalline phases almost resonant cross-relaxation between $\mathrm{Er}^{3+}$ and $\mathrm{Yb}^{3+}$ ions $\left({ }^{2} \mathrm{H}_{9 / 2},{ }^{4} \mathrm{~F}_{7 / 2} \rightarrow{ }^{4} \mathrm{~F}_{9 / 2},{ }^{4} \mathrm{~F}_{5 / 2}\right)$ populates ${ }^{4} \mathrm{~F}_{9 / 2}$. This cross-relaxation mechanism is highly efficient in the investigated materials, as the result intense red UCL is observed.

The local environment of $\mathrm{Er}^{3+}$ ions in the glass ceramics was investigated using site-selective spectroscopy. The luminescence spectra of the green emission of $\mathrm{Er}^{3+}$ ions in the glass

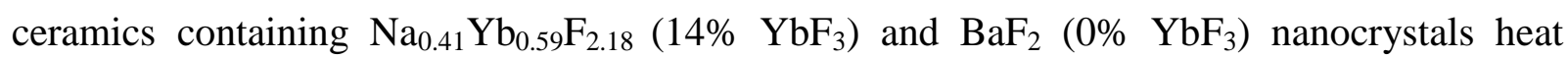
treated at $650^{\circ} \mathrm{C}$ for $2 \mathrm{~h}$ are shown in Fig. 8. 

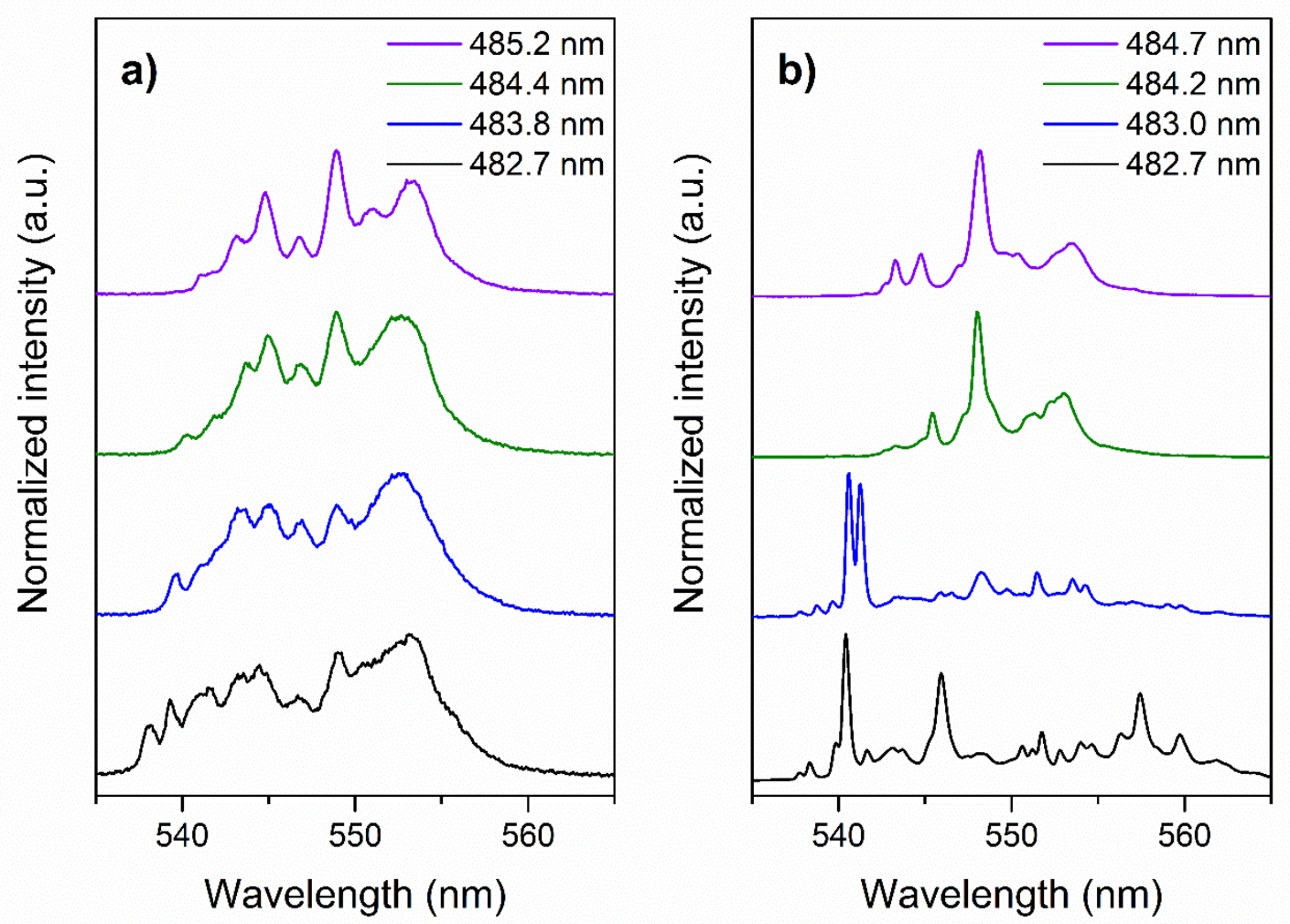

Fig. 8. Luminescence spectra (exciting ${ }^{4} \mathrm{~F}_{7 / 2}$, monitoring ${ }^{4} \mathrm{~S}_{3 / 2} \rightarrow{ }^{4} \mathrm{I}_{15 / 2}$ emission) of $\mathrm{Er}^{3+}$ ions in the glass ceramics with a) $14 \% \mathrm{YbF}_{3}$ and b) $0 \% \mathrm{YbF}_{3}$ heat treated at $650^{\circ} \mathrm{C}$ for $2 \mathrm{~h}$. The luminescence spectra are detected at $10 \mathrm{~K}$.

Considerable changes in the luminescence spectra of both samples were detected when the excitation wavelength was varied. The fine structure of $\mathrm{Er}^{3+}$ luminescence can change if $\mathrm{Er}^{3+}$ ions are incorporated in several different cationic positions in the crystalline lattice. Multiple comparable spectra were detected for the glass ceramics with $14 \% \mathrm{YbF}_{3}$, indicating the incorporation of $\mathrm{Er}^{3+}$ ions in similar local environment, which is characteristic to solid solutions (see Fig. 8 a). In $\mathrm{BaF}_{2}$ containing glass ceramics $\left(0 \% \mathrm{YbF}_{3}\right)$ two distinct (excited at 482.7 and $483.0 \mathrm{~nm}$ ) and several similar (excited in the region 484-485 $\mathrm{nm}$ ) spectra could be detected (see Fig. 8 b).

Seven different $\mathrm{Er}^{3+}$ sites have been detected in $\mathrm{BaF}_{2}$ single crystals, six of them arising from $\mathrm{Er}^{3+}$ clusters [14]. The luminescence spectrum excited at $483.0 \mathrm{~nm}$ is similar to spectra of 
single $\mathrm{Er}^{3+}$ site with trigonal symmetry characteristic to $\mathrm{BaF}_{2}$ crystals with low $\mathrm{Er}^{3+}$ content $[14,58]$. The other spectra are associated with different $\mathrm{Er}^{3+}$ cluster sites.
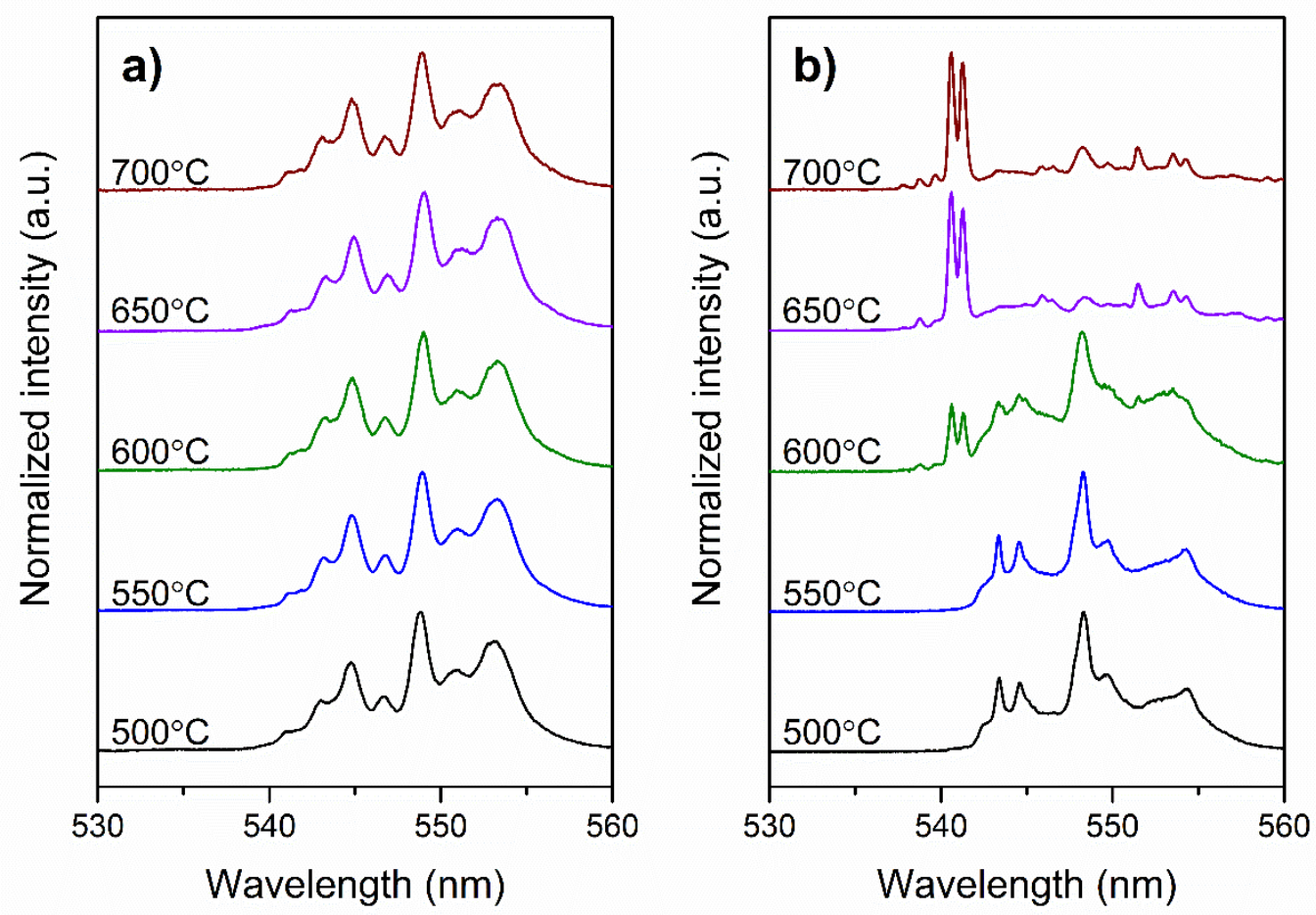

Fig. 9. Luminescence spectra of $\mathrm{Er}^{3+}$ ions in the glass ceramics with a) $14 \% \mathrm{YbF}_{3}$ (excited at $483.0 \mathrm{~nm}$ ) and $0 \% \mathrm{YbF}_{3}$ (exited at $485.2 \mathrm{~nm}$ ) detected at $10 \mathrm{~K}$.

Despite the increase of the size of nanocrystals after the heat treatment at higher temperature, no changes in luminescence spectra were detected for the glass ceramics containing $\mathrm{Na}_{0.5}$ ${ }_{x} \mathrm{Yb}_{0.5+\mathrm{x}} \mathrm{F}_{2+2 \mathrm{x}}$ solid solutions (See Fig. 9 a). In the glass ceramics with $0 \% \mathrm{YbF}_{3}$, on the contrary, considerable deviations of the local environment of $\mathrm{Er}^{3+}$ ions during the growth of $\mathrm{BaF}_{2}$ nanocrystals were observed. Despite being present in all the glass ceramics with $0 \%$ $\mathrm{YbF}_{3}$, the relative intensity ratio of different $\mathrm{Er}^{3+}$ sites was found to be dependent on the temperature of the heat treatment.

In the glass ceramics heat treated at $500-550^{\circ} \mathrm{C}$ for $2 \mathrm{~h}$ the $\mathrm{Er}^{3+}$ clusters were found to be dominant, however, the heat treatment at higher temperature resulted in the enhancement of the relative intensity of the isolated $\mathrm{Er}^{3+}$ site (see Fig. 9 b) indicating the decrease of $\mathrm{Er}^{3+}$ content in $\mathrm{BaF}_{2}$ during the growth of the nanocrystals. The results suggest that $\mathrm{Er}^{3+}$ ions act as 
nucleating agents and therefore at low temperature of heat treatment $\mathrm{Er}^{3+}$ clusters are formed, however, during the growth of the crystals, the surrounding regions are depleted in $\mathrm{Er}^{3+}$ ions, as the result isolated $\mathrm{Er}^{3+}$ sites can be formed.

In the glass ceramics with distorted fluorite type phases, considerable deviations in the luminescence spectra were observed after different heat treatment suggesting changes in the local environment of $\mathrm{Er}^{3+}$ ions during the crystallization.
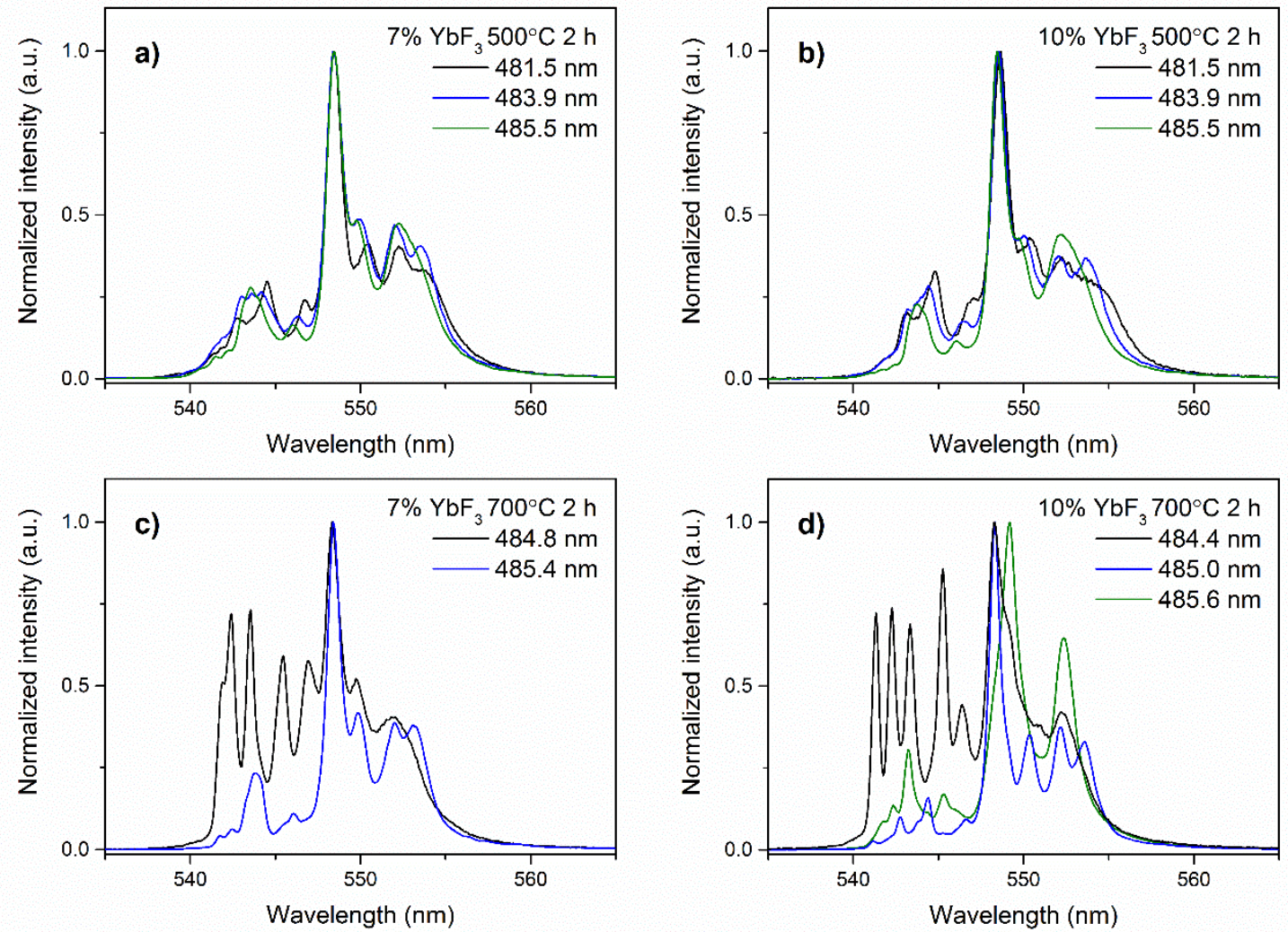

Fig. 10. Luminescence spectra (exciting ${ }^{4} \mathrm{~F}_{7 / 2}$, monitoring ${ }^{4} \mathrm{~S}_{3 / 2} \rightarrow{ }^{4} \mathrm{I}_{15 / 2}$ emission) of $\mathrm{Er}^{3+}$ ions in the glass ceramics with a,c) $7 \% \mathrm{YbF}_{3}$ and b,d) $10 \% \mathrm{YbF}_{3}$ heat treated at a-b) $500^{\circ} \mathrm{C}$ and c-d) $650^{\circ} \mathrm{C}$ for $2 \mathrm{~h}$. The luminescence spectra are detected at $10 \mathrm{~K}$.

The luminescence spectra of the glass ceramics with $7 \%$ and $10 \% \mathrm{YbF}_{3}$ detected at $10 \mathrm{~K}$ are shown in Fig. 10. According to the XRD data (see Fig. 2) no detectable distortion in the fluorite lattice is observed for the glass ceramics heat treated at $500^{\circ} \mathrm{C}$ for $2 \mathrm{~h}$. Similar relatively broad luminescence spectra originating from multiple $\mathrm{Er}^{3+}$ sites confirm the formation of fluorite type solid solutions. 
After the heat treatment at higher temperature (see Fig. $10 \mathrm{c}-\mathrm{d}$ ) several distinct spectra with sharp luminescence bands can be observed indicating the ordering of the fluorite lattice.

In the glass ceramics containing rhombohedral $\mathrm{Ba}_{4} \mathrm{Yb}_{3} \mathrm{~F}_{17}\left(7 \% \mathrm{YbF}_{3}\right)$ two distinct spectra have been detected suggesting the incorporation of $\mathrm{Er}^{3+}$ ions into two different positions in the crystalline lattice.

In the rhombohedral $\mathrm{Ba}_{4} \mathrm{Yb}_{3} \mathrm{~F}_{17}$ there are three cationic positions - two un-equivalent $\mathrm{Ba}^{2+}$ positions with $\mathrm{C}_{1}$ and $\mathrm{C}_{3}$ symmetry and one $\mathrm{Yb}^{3+}$ position with $\mathrm{C}_{1}$ symmetry [59]. The crystal structure of the rhombohedral $\mathrm{Ba}_{4} \mathrm{Yb}_{3} \mathrm{~F}_{17}$ is shown in Fig. 11 .

a)

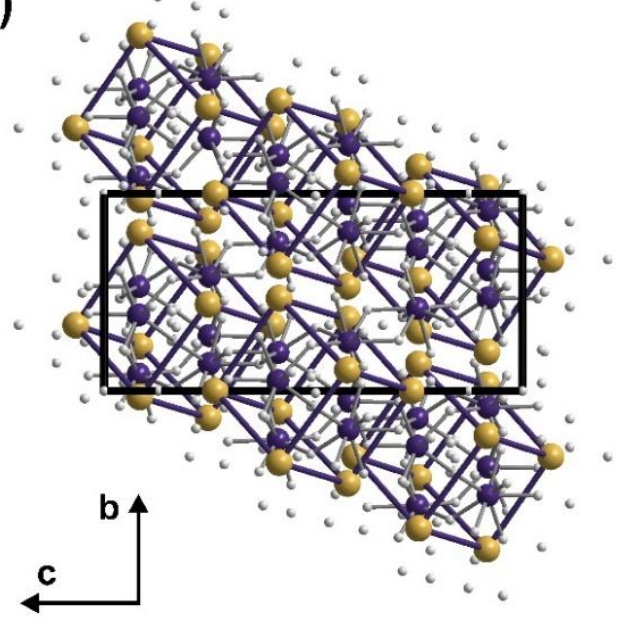

b)

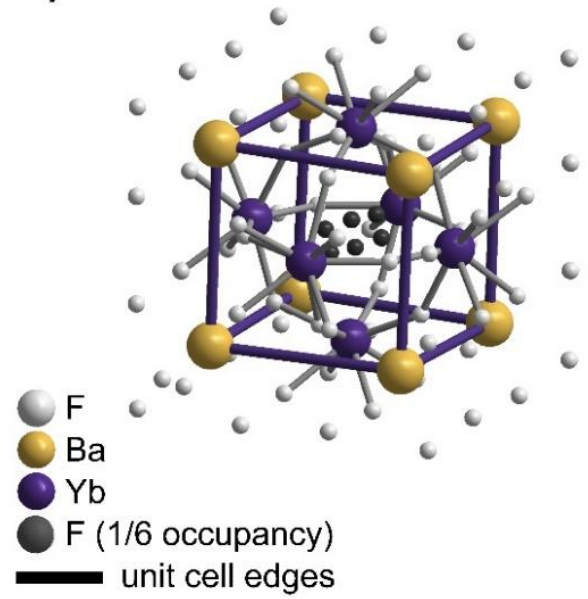

Fig. 11. a) Crystal structure of the rhombohedral $\mathrm{Ba}_{4} \mathrm{Yb}_{3} \mathrm{~F}_{17}$, projection along a axis and b) $\mathrm{Ba}_{8} \mathrm{Yb}_{6} \mathrm{~F}_{68}$ structural unit. Atomic positions taken from [59].

According to [59], in $\mathrm{Ba}_{4} \mathrm{Yb}_{3} \mathrm{~F}_{17} \mathrm{Yb}^{3+}$ ions are composed in octahedral clusters $\mathrm{Yb}_{6} \mathrm{~F}_{36}$ that form $\mathrm{Ba}_{8} \mathrm{Yb}_{6} \mathrm{~F}_{68}$ structural units.

The $\mathrm{Er}^{3+}$ ions in the crystalline lattice are expected to replace $\mathrm{Yb}^{3+}$ positions rather than $\mathrm{Ba}^{2+}$. The incorporation of $\mathrm{Er}^{3+}$ ions in a single cationic position, presumably $\mathrm{RE}^{3+}$, was observed in $\mathrm{Ba}_{4} \mathrm{Gd}_{3} \mathrm{~F}_{17}$ and $\mathrm{Ba}_{4} \mathrm{Y}_{3} \mathrm{~F}_{17}$ containing glass ceramics [39,40].

The multisite formation observed in the investigated glass ceramics could be caused by several factors such as deviations in the chemical composition due to formation of non-stoichiometric rhombohedral phase, incorporation of $\mathrm{Na}^{+}$ions in the crystalline lattice or partial replacement 
of $\mathrm{F}^{-}$with $\mathrm{O}^{2-}$ in the centre of octahedral clusters, however, further investigation is required to fully clarify the details.

In the tetragonally distorted phase formed in the glass ceramics with $10 \% \mathrm{YbF}_{3}$, three distinct spectra that are similar to tetragonal $\mathrm{NaF}-\mathrm{BaF}_{2}-\mathrm{YF}_{3}$ reported previously [39], were detected. However, there is also considerable resemblance with the rhombohedral $\mathrm{Ba}_{4} \mathrm{Yb}_{3} \mathrm{~F}_{17}$ indirectly suggesting the presence of similar structural elements (such as $\mathrm{Yb}_{6} \mathrm{~F}_{36}$ clusters) in both of these phases.

The changes in the local environment of $\mathrm{Er}^{3+}$ ions associated with the ordering of fluorite phases in the glass ceramics were used for the determination of the phase transition temperature. Luminescence excitation and luminescence spectra of the glass ceramics with $7 \%$ $\mathrm{YbF}_{3}$ heat treated at $500-700^{\circ} \mathrm{C}$ for $2 \mathrm{~h}$ are shown in Fig. 12.
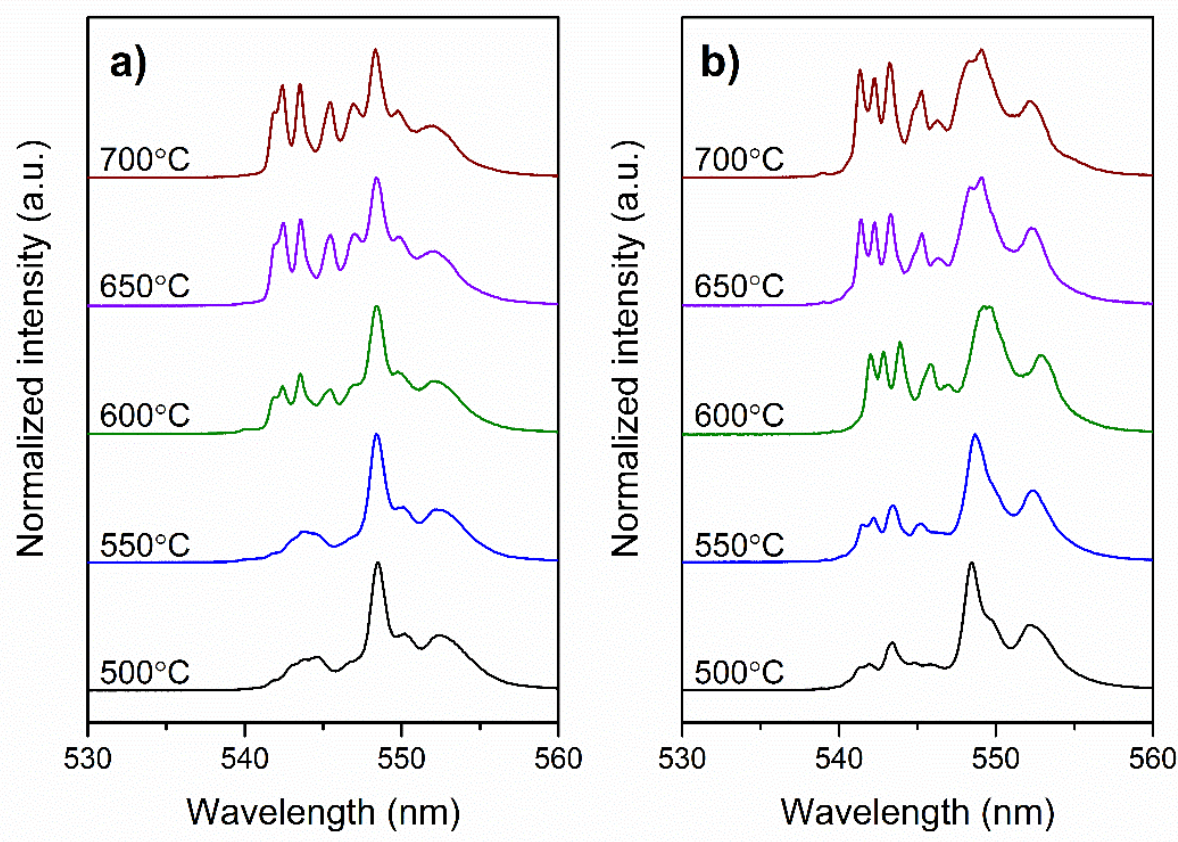

Fig. 12 Luminescence spectra of $\mathrm{Er}^{3+}$ ions in the glass ceramics with a) $7 \% \mathrm{YbF}_{3}$ (excited at $484.8 \mathrm{~nm}$ ) and $10 \% \mathrm{YbF}_{3}$ (exited at $484.4 \mathrm{~nm}$ ) detected at $10 \mathrm{~K}$.

In the glass ceramics heat-treated at $500-550^{\circ} \mathrm{C}$ relatively broad luminescence bands due to overlapping of the luminescence spectra of several $\mathrm{Er}^{3+}$ sites in the cubic solid solutions are detected. Considerable changes in the luminescence spectra are observed after the heat treatment at $600-650^{\circ} \mathrm{C}$ for $2 \mathrm{~h}$ in the glass ceramics with $7 \% \mathrm{YbF}_{3}$. This temperature region 
is associated with the phase transition from fluorite-type to rhombohedrally distorted fluorite phase $-\mathrm{Ba}_{4} \mathrm{Yb}_{3} \mathrm{~F}_{17}$ and agrees well with the exothermal effect $\mathrm{T}_{\mathrm{c} 2}$ detected in the DTA data (see Fig. 1).

Similar ordering processes occur in the glass ceramics with $10 \% \mathrm{YbF}_{3}$ (see Fig. 12 b). The tetragonally distorted phase is formed after the heat treatment at $600^{\circ} \mathrm{C}$ and the characteristic splitting is also detected in the XRD patterns confirming the phase transition from the metastable cubic to the tetragonal fluorite related solid-solution with composition of NaF$\mathrm{BaF}_{2}-\mathrm{YbF}_{3}$.

\section{Conclusions}

For the first time nanocrystalline erbium doped glass ceramics containing rhombohedral $\mathrm{Ba}_{4} \mathrm{Yb}_{3} \mathrm{~F}_{17}$ and tetragonal $\mathrm{NaF}-\mathrm{BaF}_{2}-\mathrm{YbF}_{3}$ ordered fluorite related phases were prepared from melt-quenched precursor glasses.

Intense red upconversion luminescence observed under near-infrared excitation is explained by efficient cross-relaxation processes between erbium and ytterbium ions.

In $\mathrm{BaF}_{2}$ nanocrystallites containing glass ceramics luminescence corresponding to isolated $\mathrm{Er}^{3+}$ sites and their clusters was detected. For the glass ceramics heat treated at lower temperature the formation of the cluster sites was dominant, whereas the heat treatment of the glass ceramics at higher temperatures increased the relative number of single $\mathrm{Er}^{3+}$ sites in $\mathrm{BaF}_{2}$ nanocrystals suggesting that $\mathrm{Er}^{3+}$ ions act as nucleating agents during the crystallization of $\mathrm{BaF}_{2}$.

The introduction of $\mathrm{YbF}_{3}$ in the precursor glass promoted the formation of solid solutions with fluorite-type structure. The results of DTA, XRD as well as site-selective spectroscopy data analysis demonstrate the ordering of fluorite-type structure upon the heat treatment of the precursor glasses. Two ordered phases with rhombohedrally $\left(\mathrm{Ba}_{4} \mathrm{Yb}_{3} \mathrm{~F}_{17}\right.$ for glass ceramics with low $\mathrm{YbF}_{3}$ content) and tetragonally $\left(\mathrm{NaF}-\mathrm{BaF}_{2}-\mathrm{YbF}_{3}\right.$ solid solution in the glass ceramics with higher $\mathrm{YbF}_{3}$ content) distorted fluorite structure were confirmed.

The results show that the site-selective spectroscopy of rare earth ions is an essential tool to study the phase formation of the nanocrystalline structures. 


\section{Acknowledgements}

This work was supported by National Research Program IMIS2 and Arnis Riekstins "MikroTik" donation. Donations are administered by the University of Latvia Foundation.

\section{References}

[1] M. Sobczyk, Temperature-dependent luminescence and temperature-stimulated NIRto-VIS up-conversion in $\mathrm{Nd}^{3+}$-doped $\mathrm{La}_{2} \mathrm{O}_{3}-\mathrm{Na}_{2} \mathrm{O}-\mathrm{ZnO}-\mathrm{TeO}_{2}$ glasses, J. Quant. Spectrosc. Radiat. Transf. 119 (2013) 128-136. doi:10.1016/j.jqsrt.2012.12.025.

[2] K. Presley, J. Hwang, S. Cheong, R. Tilley, J. Collins, M. Viapiano, J. Lannutti, Nanoscale upconversion for oxygen sensing, Mater. Sci. Eng. C. 70 (2017) 76-84. doi:10.1016/j.msec.2016.08.056.

[3] J.-C. Boyer, C.-J. Carling, B.D. Gates, N.R. Branda, Two-Way Photoswitching Using One Type of Near-Infrared Light, Upconverting Nanoparticles, and Changing Only the Light Intensity, J. Am. Chem. Soc. 132 (2010) 15766-15772. doi:10.1021/ja107184z.

[4] Y. Zhou, S.-T. Han, X. Chen, F. Wang, Y.-B. Tang, V.A.L. Roy, An upconverted photonic nonvolatile memory, Nat. Commun. 5 (2014) 4720. doi:10.1038/ncomms5720.

[5] C. Zhang, H.-P. Zhou, L.-Y. Liao, W. Feng, W. Sun, Z.-X. Li, C.-H. Xu, C.-J. Fang, L.-D. Sun, Y.-W. Zhang, C.-H. Yan, Luminescence Modulation of Ordered Upconversion Nanopatterns by a Photochromic Diarylethene: Rewritable Optical Storage with Nondestructive Readout, Adv. Mater. 22 (2010) 633-637. doi:10.1002/adma.200901722.

[6] A. Shalav, B.S. Richards, M.A. Green, Luminescent layers for enhanced silicon solar cell performance: Up-conversion, Sol. Energy Mater. Sol. Cells. 91 (2007) 829-842. doi:10.1016/j.solmat.2007.02.007.

[7] J.C. Goldschmidt, S. Fischer, Upconversion for Photovoltaics - a Review of Materials, Devices and Concepts for Performance Enhancement, Adv. Opt. Mater. 3 (2015) 510-535. doi:10.1002/adom.201500024. 
[8] R. Deng, F. Qin, R. Chen, W. Huang, M. Hong, X. Liu, Temporal full-colour tuning through non-steady-state upconversion, Nat. Nanotechnol. 10 (2015) 237-242. doi:10.1038/nnano.2014.317.

[9] E. Downing, L. Hesselink, J. Ralston, R. Macfarlane, A Three-Color, Solid-State, Three-Dimensional Display, Science. $273 \quad$ (1996) 1185-1189. doi:10.1126/science.273.5279.1185.

[10] Q. Liu, W. Feng, T. Yang, T. Yi, F. Li, Upconversion luminescence imaging of cells and small animals, Nat. Protoc. 8 (2013) 2033-2044. doi:10.1038/nprot.2013.114.

[11] N.M. Idris, M.K. Gnanasammandhan, J. Zhang, P.C. Ho, R. Mahendran, Y. Zhang, In vivo photodynamic therapy using upconversion nanoparticles as remote-controlled nanotransducers, Nat. Med. 18 (2012) 1580-1585. doi:10.1038/nm.2933.

[12] D. Chen, L. Liu, P. Huang, M. Ding, J. Zhong, Z. Ji, $\mathrm{Nd}^{3+}-$ Sensitized Ho ${ }^{3+}$ Single-Band Red Upconversion Luminescence in Core-Shell Nanoarchitecture, J. Phys. Chem. Lett. 6 (2015) 2833-2840. doi:10.1021/acs.jpclett.5b01180.

[13] D.N. Patel, R.B. Reddy, S.K. Nash-Stevenson, Diode-pumped violet energy upconversion in $\mathrm{BaF}_{2}: \mathrm{Er}^{3+}$, Appl. Opt. 37 (1998) 7805. doi:10.1364/AO.37.007805.

[14] M.P. Miller, J.C. Wright, Single site multiphonon and energy transfer relaxation phenomena in $\mathrm{BaF}_{2}: \mathrm{Er}^{3+}$, J. Chem. Phys. 68 (1978) 1548-1562. doi:10.1063/1.435924.

[15] B.P. Sobolev, N.L. Tkachenko, Phase diagrams of $\mathrm{BaF}_{2}-(\mathrm{Y}, \mathrm{Ln}) \mathrm{F}_{3}$ systems, J. Less Common Met. 85 (1982) 155-170. doi:10.1016/0022-5088(82)90067-4.

[16] M. Kieser, O. Greis, Preparation, thermal characterization and x-ray powder diffraction of $\mathrm{Ba}_{2} \mathrm{REF}_{7}$ superstructure phases ( $\mathrm{RE} \equiv \mathrm{Dy}-\mathrm{Lu}, \mathrm{Y}$ ), J. Less Common Met. 71 (1980) 63-69. doi:10.1016/0022-5088(80)90101-0.

[17] B.P. Sobolev, Non-stoichiometry in inorganic fluorides and phases with fluorite structure, Butll. Soc. Cat. Cien. J. 12 (1991) 275-332.

[18] P.P. Fedorov, A.A. Luginina, A.I. Popov, Transparent oxyfluoride glass ceramics, J. Fluor. Chem. 172 (2015) 22-50. doi:10.1016/j.jfluchem.2015.01.009. 
[19] D. Chen, Z. Wan, S. Liu, Highly Sensitive Dual-Phase Nanoglass-Ceramics SelfCalibrated Optical Thermometer, Anal. Chem. 88 (2016) 4099-4106. doi:10.1021/acs.analchem.6b00434.

[20] D. Chen, Z. Wan, Y. Zhou, X. Zhou, Y. Yu, J. Zhong, M. Ding, Z. Ji, Dual-Phase Glass Ceramic: Structure, Dual-Modal Luminescence, and Temperature Sensing Behaviors, ACS Appl. Mater. Interfaces. 7 (2015) 19484-19493. doi:10.1021/acsami.5b06036.

[21] D. Chen, S. Liu, X. Li, Z. Wan, S. Li, Gd-based oxyfluoride glass ceramics: Phase transformation, optical spectroscopy and upconverting temperature sensing, J. Eur. Ceram. Soc. 37 (2017) 4083-4094. doi:10.1016/j.jeurceramsoc.2017.05.006.

[22] H. Fu, X. Qiao, S. Cui, Q. Luo, J. Qian, X. Fan, X. Zhang, Tunable white light emission from glass-ceramics containing $\mathrm{Eu}^{2+}, \mathrm{Tb}^{3+}, \mathrm{Eu}^{3+}$ co-doped $\mathrm{SrLaF}_{5}$ nanocrystals, Mater. Lett. 71 (2012) 15-17. doi:10.1016/j.matlet.2011.12.004.

[23] C. Li, S. Xu, R. Ye, D. Deng, Y. Hua, S. Zhao, S. Zhuang, White up-conversion emission in $\mathrm{Ho}^{3+} / \mathrm{Tm}^{3+} / \mathrm{Yb}^{3+}$ tri-doped glass ceramics embedding $\mathrm{BaF}_{2}$ nanocrystals, Phys. B Condens. Matter. 406 (2011) 1698-1701. doi:10.1016/j.physb.2011.01.073.

[24] B.N. Samson, P. a Tick, N.F. Borrelli, Efficient neodymium-doped glass-ceramic fiber laser and amplifier., Opt. Lett. 26 (2001) 145-147. doi:10.1364/OL.26.000145.

[25] M. Reben, D. Dorosz, J. Wasylak, B. Burtan, J. Jaglarz, J. Zontek, Nd ${ }^{3+}$-doped oxyfluoride glass ceramics optical fibre with $\mathrm{SrF}_{2}$ nanocrystals, Opt. Appl. XLII (2012). doi:10.5277/oa120213.

[26] G. Lee, N. Savage, B. Wagner, Y. Zhang, B. Jacobs, H. Menkara, C. Summers, Z. Kang, Synthesis and Luminescence Properties of Transparent Nanocrystalline $\mathrm{GdF}_{3}$ :Tb GlassCeramic Scintillator., J. Lumin. 147 (2014) 363-366. doi:10.1016/j.jlumin.2013.11.073.

[27] L. Huang, S. Jia, Y. Li, S. Zhao, D. Deng, H. Wang, G. Jia, Y. Hua, S. Xu, Enhanced emissions in $\mathrm{Tb}^{3+}$-doped oxyfluoride scintillating glass ceramics containing $\mathrm{BaF}_{2}$ nanocrystals, Nucl. Instruments Methods Phys. Res. Sect. A Accel. Spectrometers, Detect. Assoc. Equip. 788 (2015) 111-115. doi:10.1016/j.nima.2015.03.084. 
[28] Z. Chen, L. Sun, H. Zhang, G.P. Dong, M. Gecevicius, Y.Q. Liu, Y.X. Fu, C. Jiang, S.F. Zhou, J.R. Qiu, Near-infrared wavelength-dependent nonlinear transmittance tailoring in glass ceramics containing $\mathrm{Er}^{3+}: \mathrm{LaF}_{3}$ nanocrystals, J. Mater. Chem. C. 4 (2016) 6707-6712. doi:10.1039/C6TC01876A.

[29] H.K. Dan, D. Zhoua, W. Rongfei, T.M. Hau, Q. Jiao, X. Yu, J. Qiu, Up-conversion of $\mathrm{Er}^{3+} / \mathrm{Yb}^{3+}$ co-doped transparent glass-ceramics containing $\mathrm{Ba}_{2} \mathrm{LaF}_{7}$ nanocrystals, J. Rare Earths. 31 (2013) 843-848. doi:10.1016/S1002-0721(12)60368-8.

[30] Z. Li, D. Zhou, Y. Yang, Y. Gao, P. Ren, J. Qiu, Effects of $\mathrm{Li}^{+}$ions on the enhancement of up-conversion emission in $\mathrm{Ho}^{3+}-\mathrm{Yb}^{3+}$ co-doped transparent glass-ceramics containing $\mathrm{Ba}_{2} \mathrm{LaF}_{7}$ nanocrystals, Opt. Mater. (Amst). 60 (2016) 277-282. doi:10.1016/j.optmat.2016.07.029.

[31] K. Biswas, S. Balaji, D. Ghosh, A. Kalyandurg, Enhanced near-infrared to green upconversion from $\mathrm{Er}^{3+}$-doped oxyfluoride glass and glass ceramics containing $\mathrm{BaGdF}_{5}$ nanocrystals, Int. J. Appl. Glas. Sci. 8 (2017) 204-215. doi:10.1111/ijag.12241.

[32] F. Liu, Y. Wang, D. Chen, Y. Yu, E. Ma, L. Zhou, P. Huang, Upconversion emission of a novel glass ceramic containing $\mathrm{Er}^{3+}: \mathrm{BaYF}_{5}$ nano-crystals, Mater. Lett. 61 (2007) 50225025. doi:10.1016/j.matlet.2007.03.089.

[33] S. Jiang, H. Guo, X. Wei, C. Duan, M. Yin, Enhanced upconversion in $\mathrm{Ho}^{3+}$-doped transparent glass ceramics containing $\mathrm{BaYbF}_{5}$ nanocrystals, J. Lumin. 152 (2014) 195-198. doi:10.1016/j.jlumin.2013.11.030.

[34] J. Yang, H. Guo, X. Liu, H.M. Noh, J.H. Jeong, Down-shift and up-conversion luminescence in $\mathrm{BaLuF}_{5}: \mathrm{Er}^{3+}$ glass-ceramics, J. Lumin. 151 (2014) 71-75. doi:10.1016/j.jlumin.2014.02.007.

[35] Y. Fei, S. Zhao, X. Sun, L. Huang, D. Deng, S. Xu, Preparation and optical properties of $\mathrm{Eu}^{3+}$ doped and $\mathrm{Er}^{3+} / \mathrm{Yb}^{3+}$ codoped oxyfluoride glass ceramics containing $\mathrm{Ba}_{1-\mathrm{x}} \mathrm{Lu}_{\mathrm{x}} \mathrm{F}_{2+\mathrm{x}}$ nanocrystals, J. Non. Cryst. Solids. 428 (2015) 20-25. doi:10.1016/j.jnoncrysol.2015.08.004. 
[36] M. Karbowiak, J. Cichos, Does BaYF5 nanocrystals exist? - The $\mathrm{BaF}_{2}-\mathrm{YF}_{3}$ solid solution revisited using photoluminescence spectroscopy, J. Alloys Compd. 673 (2016) 258264. doi:10.1016/j.jallcom.2016.02.255.

[37] P.P. Fedorov, M.N. Mayakova, S. V. Kuznetsov, V. V. Voronov, R.P. Ermakov, K.S. Samarina, A.I. Popov, V. V. Osiko, Co-precipitation of yttrium and barium fluorides from aqueous solutions, Mater. Res. Bull. $47 \quad$ (2012) 1794-1799. doi:10.1016/j.materresbull.2012.03.027.

[38] M. Karbowiak, A. Mech, A. Bednarkiewicz, W. Stręk, Synthesis and properties of solution-processed $\mathrm{Eu}^{3+}: \mathrm{BaY}_{2} \mathrm{~F}_{8}$, J. Lumin. 114 (2005) 1-8. doi:10.1016/j.jlumin.2004.11.004.

[39] G. Krieke, A. Sarakovskis, Crystallization and upconversion luminescence of distorted fluorite nanocrystals in $\mathrm{Ba}^{2+}$ containing oxyfluoride glass ceramics, J. Eur. Ceram. Soc. 36 (2016) 1715-1722. doi:10.1016/j.jeurceramsoc.2016.01.025.

[40] G. Krieke, A. Sarakovskis, R. Ignatans, J. Gabrusenoks, Phase transitions and upconversion luminescence in oxyfluoride glass ceramics containing $\mathrm{Ba}_{4} \mathrm{Gd}_{3} \mathrm{~F}_{17}$ nanocrystals, J. Eur. Ceram. Soc. 37 (2017) 1713-1722. doi:10.1016/j.jeurceramsoc.2016.12.023.

[41] J. Rodríguez-Carvajal, Recent developments for the program FULLPROF, 2001.

[42] P.E. Werner, L. Eriksson, M. Westdahl, TREOR, a semi-exhaustive trial-and-error powder indexing program for all symmetries, J. Appl. Crystallogr. 18 (1985) 367-370. doi:10.1107/S0021889885010512.

[43] S. V Kuznetsov, P.P. Fedorov, V. V Voronov, K.S. Samarina, R.P. Ermakov, V. V Osiko, Synthesis of $\mathrm{Ba}_{4} \mathrm{R}_{3} \mathrm{~F}_{17}$ ( $\mathrm{R}$ stands for rare-earth elements) powders and transparent compacts on their base, Russ. J. Inorg. Chem. 55 (2010) 484-493. doi:10.1134/S0036023610040029.

[44] P.P. Fedorov, V.B. Aleksandrov, O.S. Bondareva, I.I. Buchinskaya, M.D. Val'kovskii, B.P. Sobolev, Concentration dependences of the unit-cell parameters of nonstoichiometric fluorite-type $\mathrm{Na}_{0.5-\mathrm{x}} \mathrm{R}_{0.5+\mathrm{x}} \mathrm{F}_{2+2 \mathrm{x}}$ phases $(\mathrm{R}=$ rare-earth elements), Crystallogr. Reports. 46 (2001) 239-245. doi:10.1134/1.1358401. 
[45] a. de Pablos-Martín, G.C. Mather, F. Muñoz, S. Bhattacharyya, T. Höche, J.R. Jinschek, T. Heil, A. Durán, M.J. Pascual, Design of oxy-fluoride glass-ceramics containing NaLaF4 nano-crystals, J. Non. Cryst. Solids. $356 \quad$ (2010) 3071-3079. doi:10.1016/j.jnoncrysol.2010.04.057.

[46] C. Bocker, J. Wiemert, C. Rüssel, The formation of strontium fluoride nano crystals from a phase separated silicate glass, J. Eur. Ceram. Soc. 33 (2013) 1737-1745. doi:10.1016/j.jeurceramsoc.2013.02.008.

[47] D. Chen, Z. Wan, Y. Zhou, Y. Chen, H. Yu, H. Lu, Z. Ji, P. Huang, Lanthanideactivated $\mathrm{Na}_{5} \mathrm{Gd}_{9} \mathrm{~F}_{32}$ nanocrystals precipitated from a borosilicate glass: Phase-separationcontrolled crystallization and optical property, J. Alloys Compd. 625 (2015) 149-157. doi:10.1016/j.jallcom.2014.11.128.

[48] A. Herrmann, M. Tylkowski, C. Bocker, C. Rüssel, Preparation and luminescence properties of glass-ceramics containing $\mathrm{Sm}^{3+-}$ doped hexagonal $\mathrm{NaGdF}_{4}$ crystals, J. Mater. Sci. 48 (2013) 6262-6268. doi:10.1007/s10853-013-7423-5.

[49] A. Sarakovskis, J. Grube, A. Mishnev, M. Springis, Up-conversion processes in $\mathrm{NaLaF}_{4}: \mathrm{Er}^{3+}$, Opt. Mater. (Amst). 31 (2009) 1517-1524. doi:10.1016/j.optmat.2009.02.015.

[50] R. Wang, X. Zhang, F. Liu, L. Xiao, Y. Chen, L. Liu, Upconversion mechanisms of $\mathrm{Er}^{3+}: \mathrm{NaYF}_{4}$ and thermal effects induced by incident photon on the green luminescence, $\mathrm{J}$. Lumin. 175 (2016) 35-43. doi:10.1016/j.jlumin.2016.02.018.

[51] J. Wang, R. Deng, M.A. MacDonald, B. Chen, J. Yuan, F. Wang, D. Chi, T.S. Andy Hor, P. Zhang, G. Liu, Y. Han, X. Liu, Enhancing multiphoton upconversion through energy clustering at sublattice level, Nat. Mater. 13 (2013) 157-162. doi:10.1038/nmat3804.

[52] X. Wu, L. Tian, Q. Lu, R. Liu, Red up-conversion emission in $\alpha-\mathrm{KYb}_{3} \mathrm{~F}_{10}: \mathrm{Er}^{3+}$ films made by electrodeposition, RSC Adv. 5 (2015) 50312-50315. doi:10.1039/C5RA07346D.

[53] Z. Wan, D. Chen, Y. Zhou, P. Huang, J. Zhong, M. Ding, H. Yu, Z. Ji, Eu ${ }^{3+}$ and Er ${ }^{3+}$ doped $\mathrm{NaLu}_{1-\mathrm{x}} \mathrm{Yb}_{\mathrm{x}} \mathrm{F}_{4} \quad(\mathrm{x}=0 \sim 1)$ solid-solution self-crystallization nano-glass-ceramics: Microstructure and optical spectroscopy, J. Eur. Ceram. Soc. 35 (2015) 3673-3679. doi:10.1016/j.jeurceramsoc.2015.05.031. 
[54] X. Li, H. Guo, Y. Wei, Y. Guo, H. Lu, H.M. Noh, J.H. Jeong, Enhanced up-conversion in $\mathrm{Er}^{3+}$-doped transparent glass-ceramics containing $\mathrm{NaYbF}_{4}$ nanocrystals, J. Lumin. 152 (2014) 168-171. doi:10.1016/j.jlumin.2013.11.042.

[55] F. Hu, J. Cao, X. Wei, X. Li, J. Cai, H. Guo, Y. Chen, C.-K. Duan, M. Yin, Luminescence properties of $\mathrm{Er}^{3+}$-doped transparent $\mathrm{NaYb}_{2} \mathrm{~F}_{7}$ glass-ceramics for optical thermometry and spectral conversion, J. Mater. Chem. C. 4 (2016) 9976-9985. doi:10.1039/C6TC03946D.

[56] D. Chen, Y. Zhou, Z. Wan, H. Yu, H. Lu, Z. Ji, P. Huang, Tunable upconversion luminescence in self-crystallized $\mathrm{Er}^{3+}: \mathrm{K}\left(\mathrm{Y}_{1-\mathrm{x}} \mathrm{Yb}_{\mathrm{x}}\right)_{3} \mathrm{~F}_{10}$ nano-glass-ceramics, Phys. Chem. Chem. Phys. 17 (2015) 7100-7103. doi:10.1039/C4CP05706F.

[57] M. Pollnau, D.R. Gamelin, S.R. Lüthi, H.U. Güdel, M.P. Hehlen, Power dependence of upconversion luminescence in lanthanide and transition-metal-ion systems, Phys. Rev. B. 61 (2000) 3337-3346. doi:10.1103/PhysRevB.61.3337.

[58] J.R. Wells, T. Dean, R.J. Reeves, Site selective spectroscopy of the $\mathrm{C}_{3 \mathrm{v}}$ symmetry centre in $\mathrm{Er}^{3+}$ doped $\mathrm{BaF}_{2}$, J. Lumin. 96 (2002) 239-248. doi:10.1016/S0022-2313(01)002307.

[59] B.A. Maksimov, K. Solans, A.P. Dudka, E.A. Genkina, M. Font-Badria, I.I. Buchinskaya, A.A. Loshmanov, A.M. Golubev, V.I. Simonov, M. Font-Altaba, others, The fluorite-matrix-based $\mathrm{Ba}_{4} \mathrm{R}_{3} \mathrm{~F}_{17}(\mathrm{R}=\mathrm{Y}, \mathrm{Yb})$ crystal structure. Ordering of cations and specific features of the anionic motif, Crystallogr. Reports. 41 (1996) 50-57. 
Click here to download high resolution image

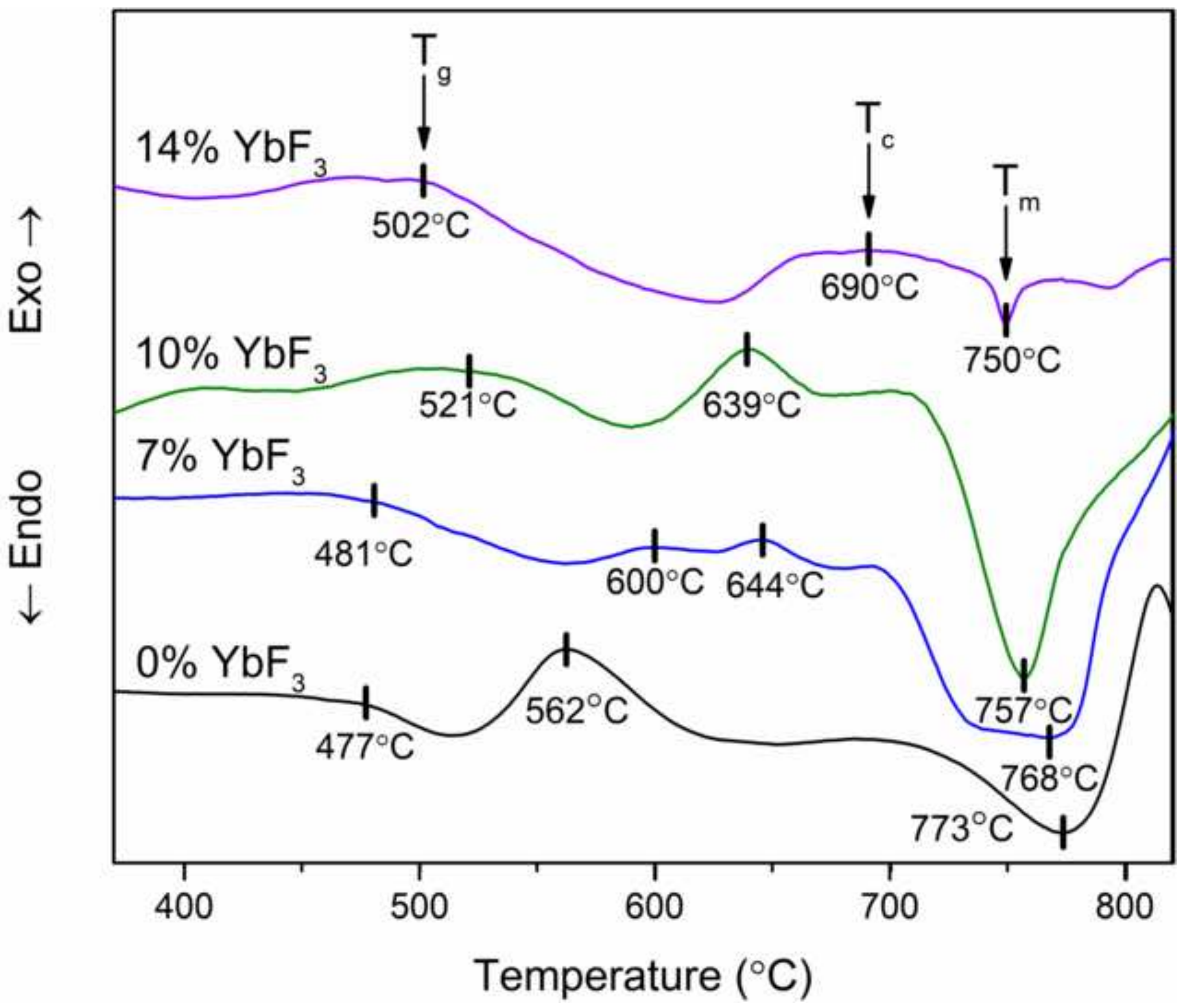




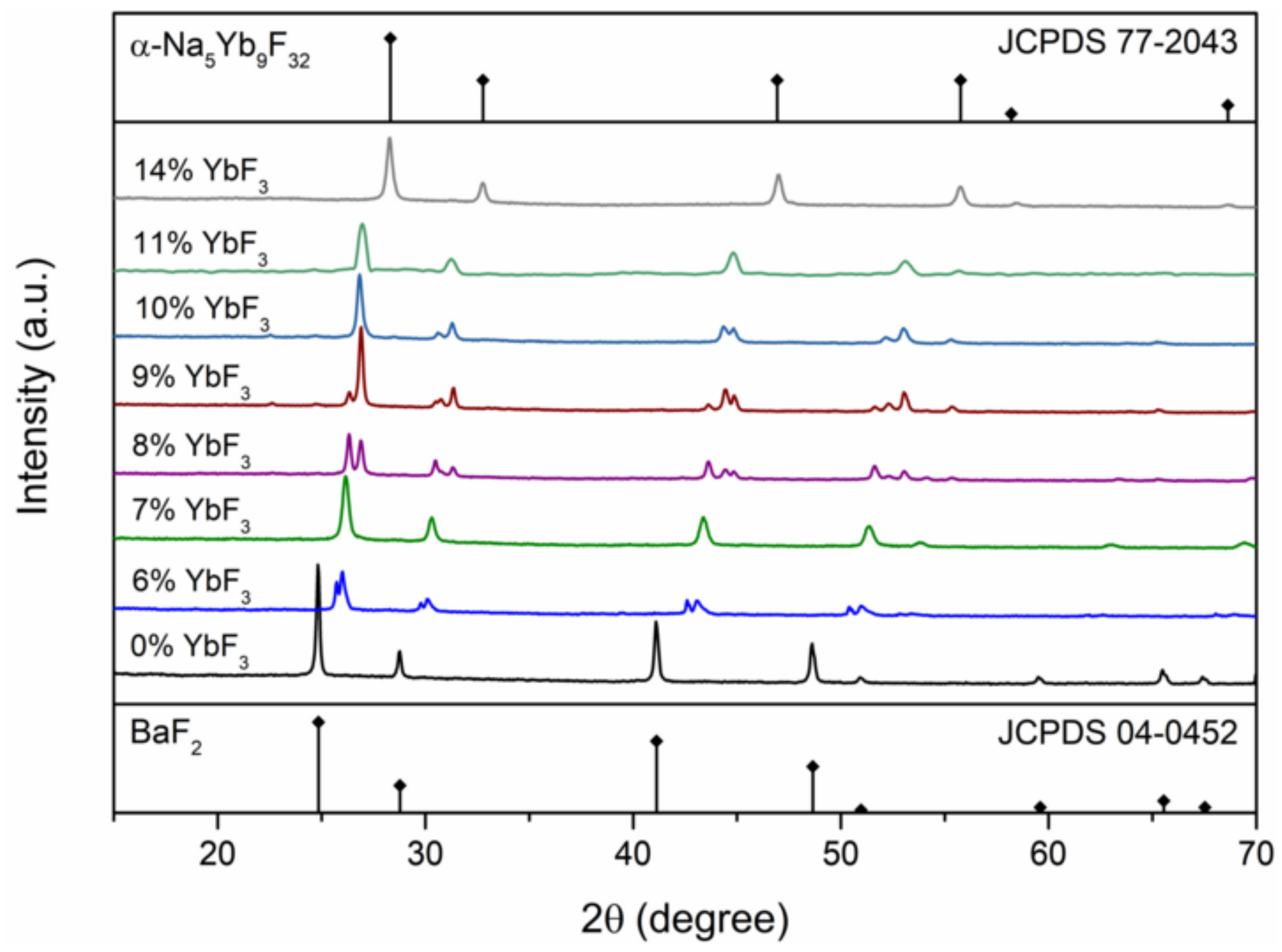



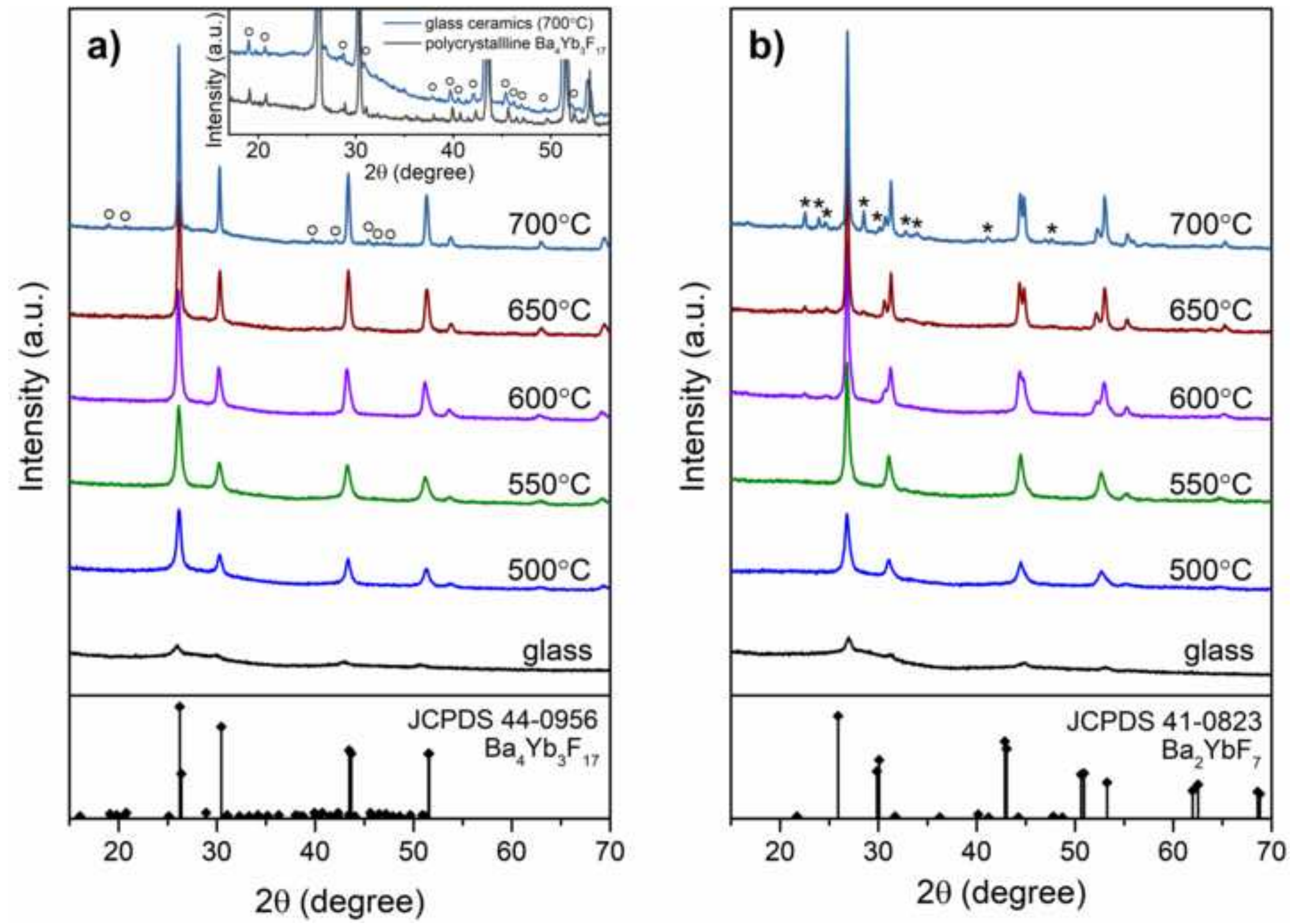
Click here to download high resolution image
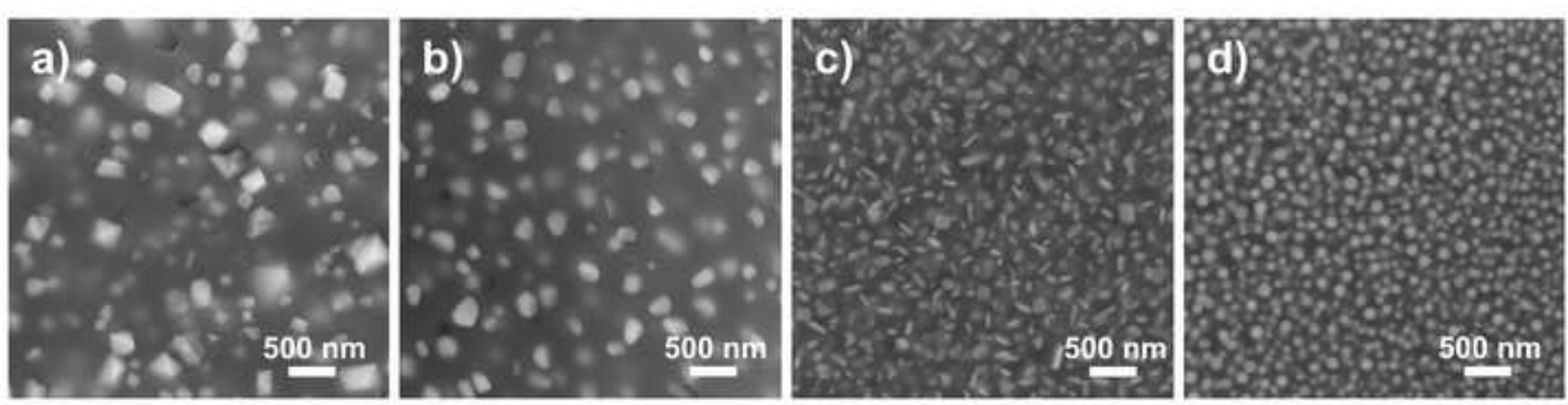


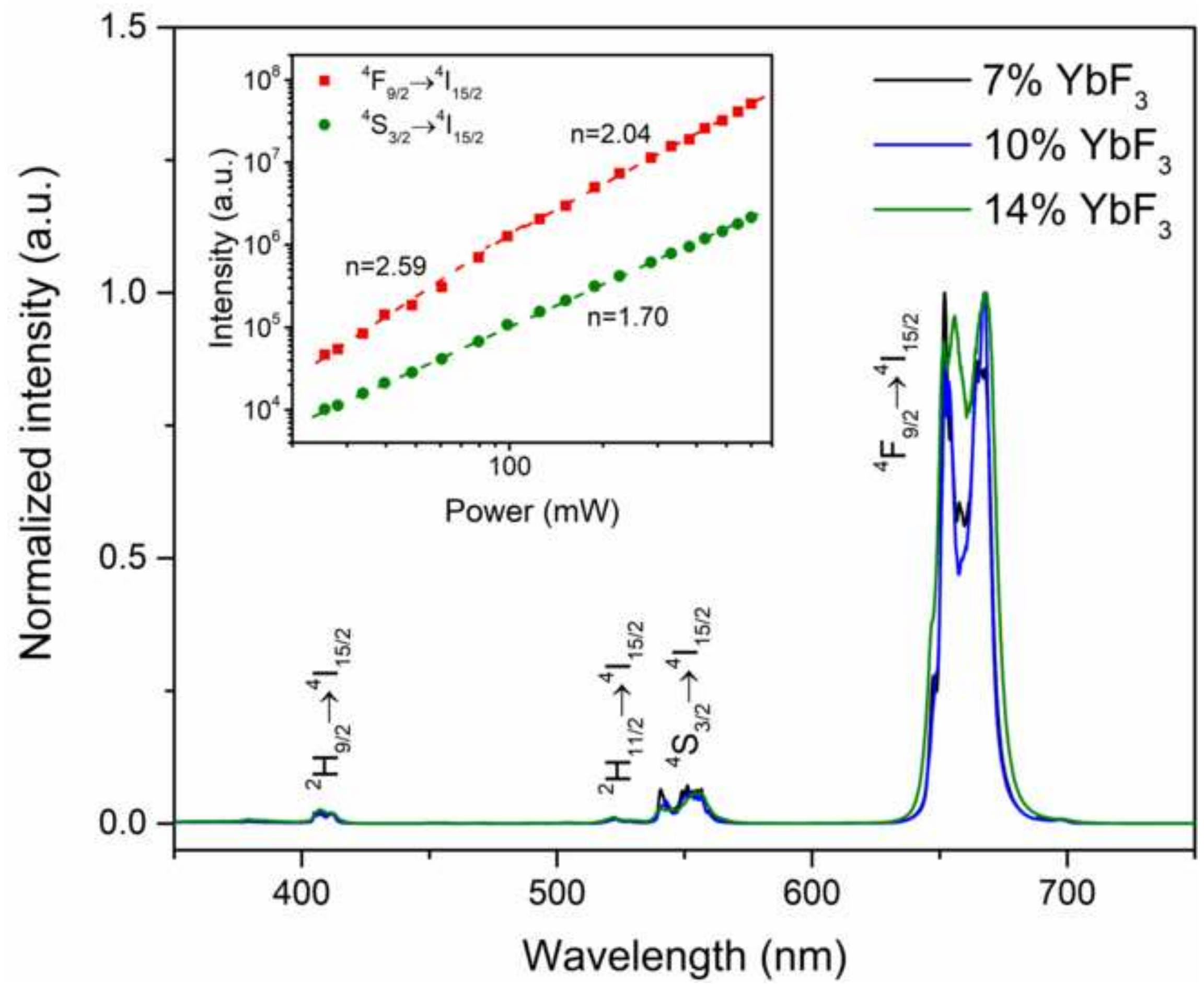



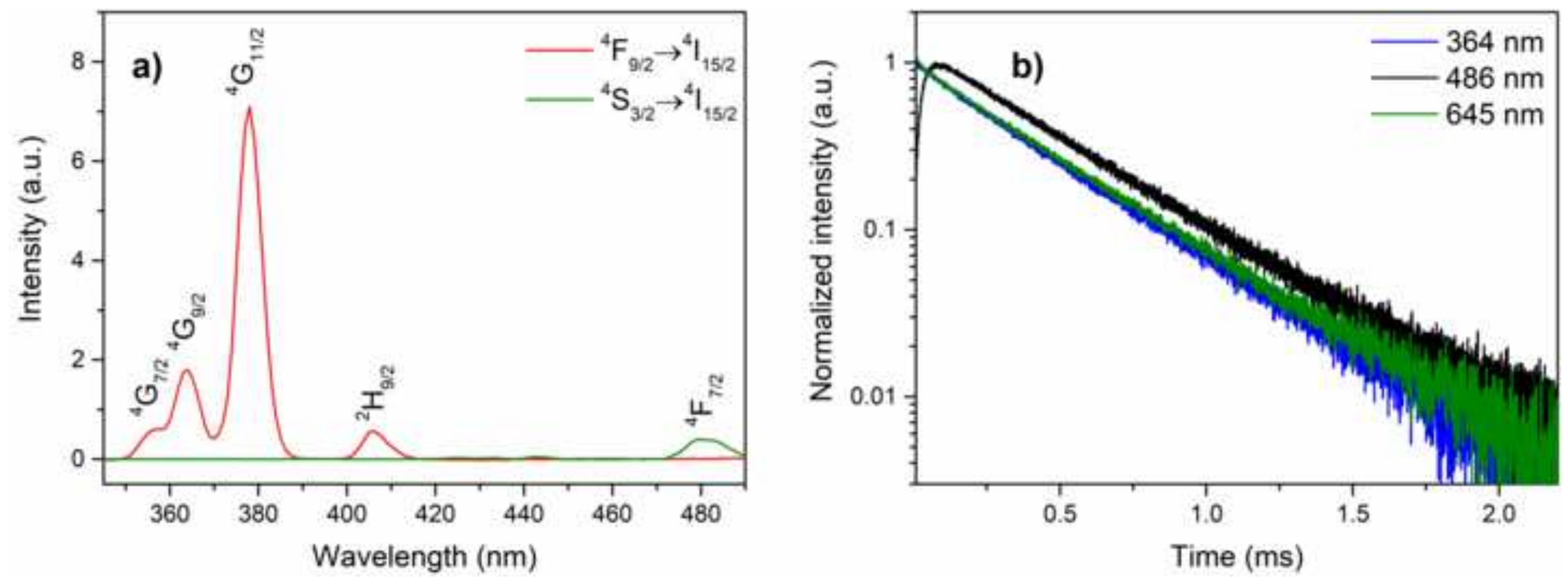


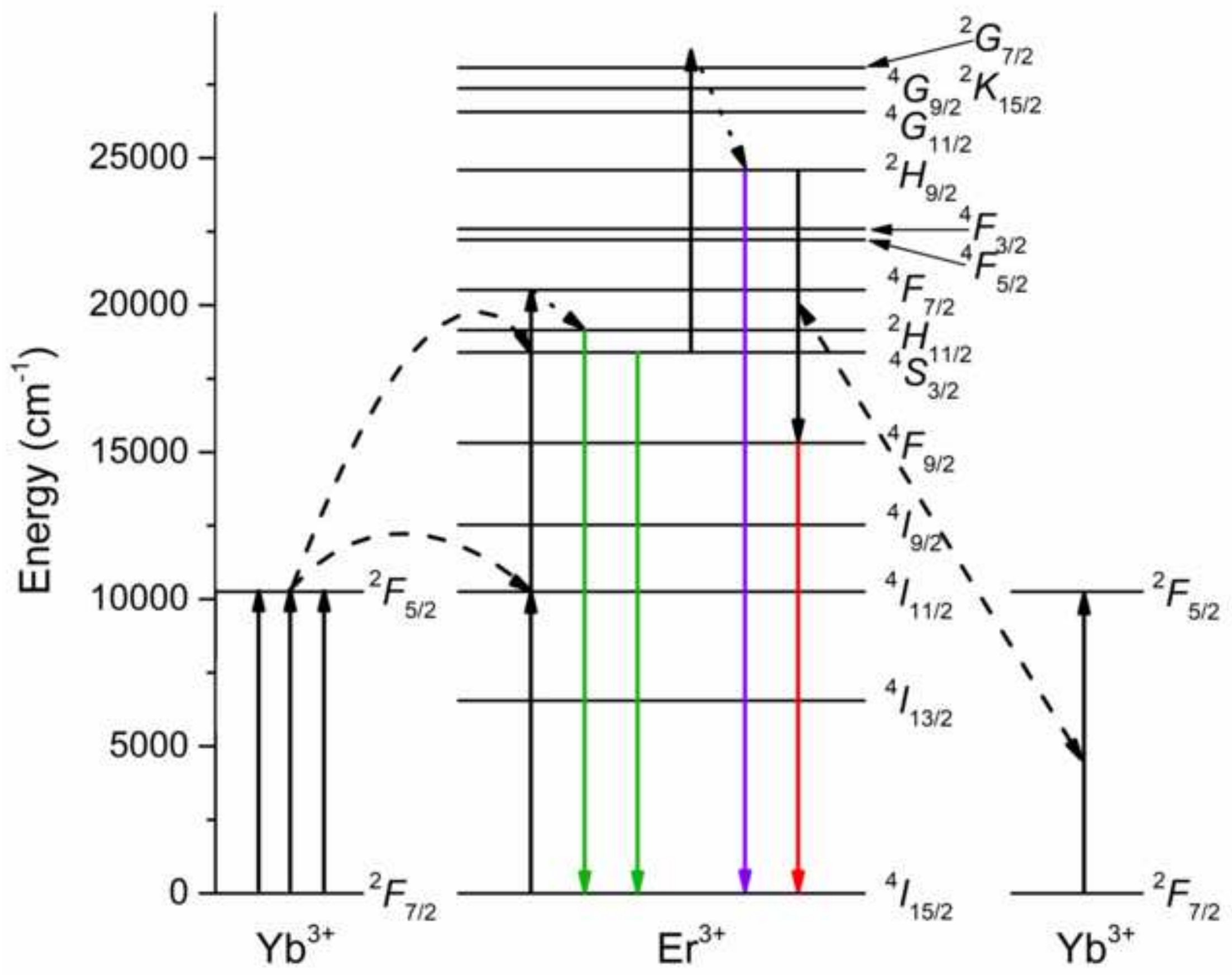



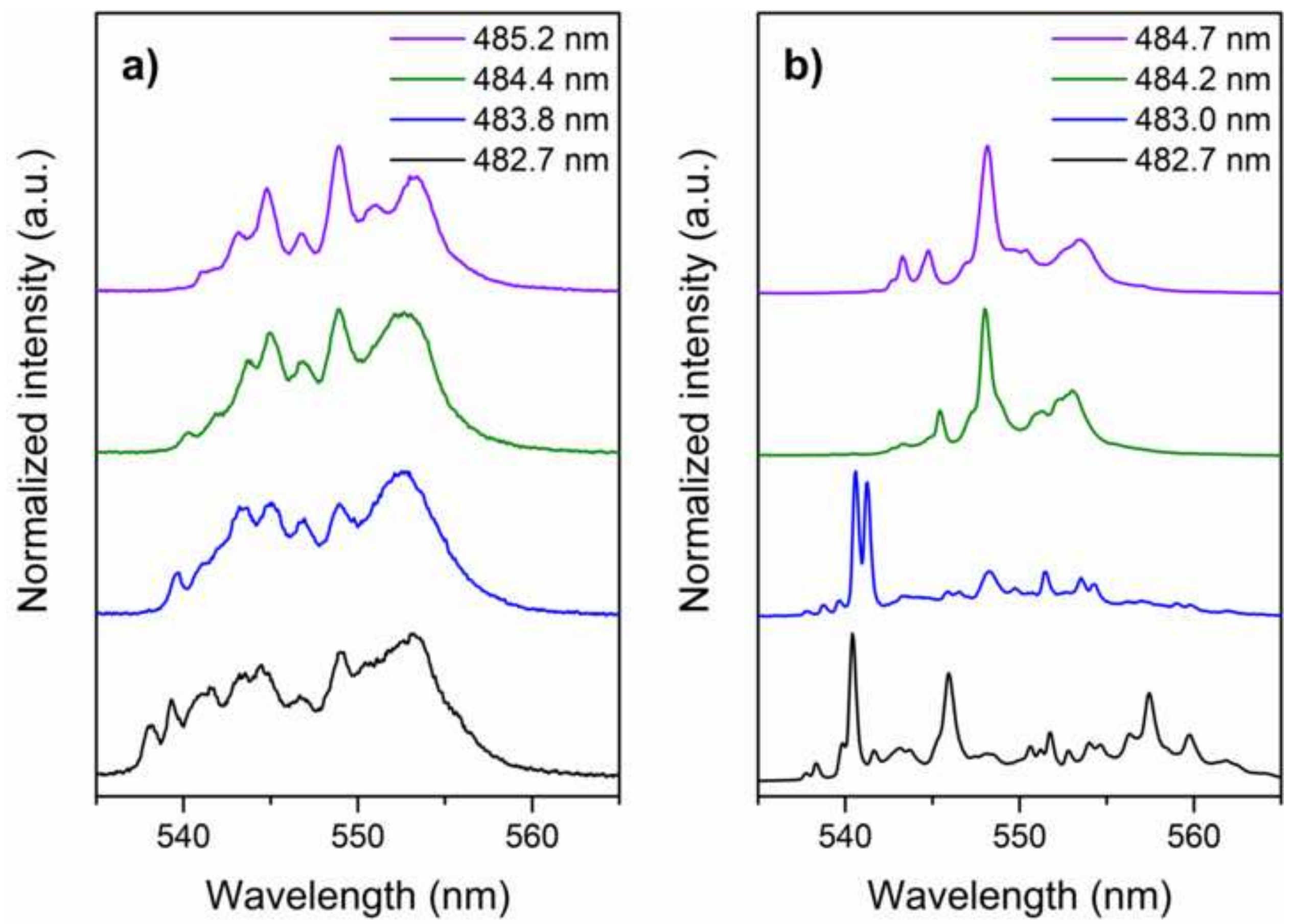

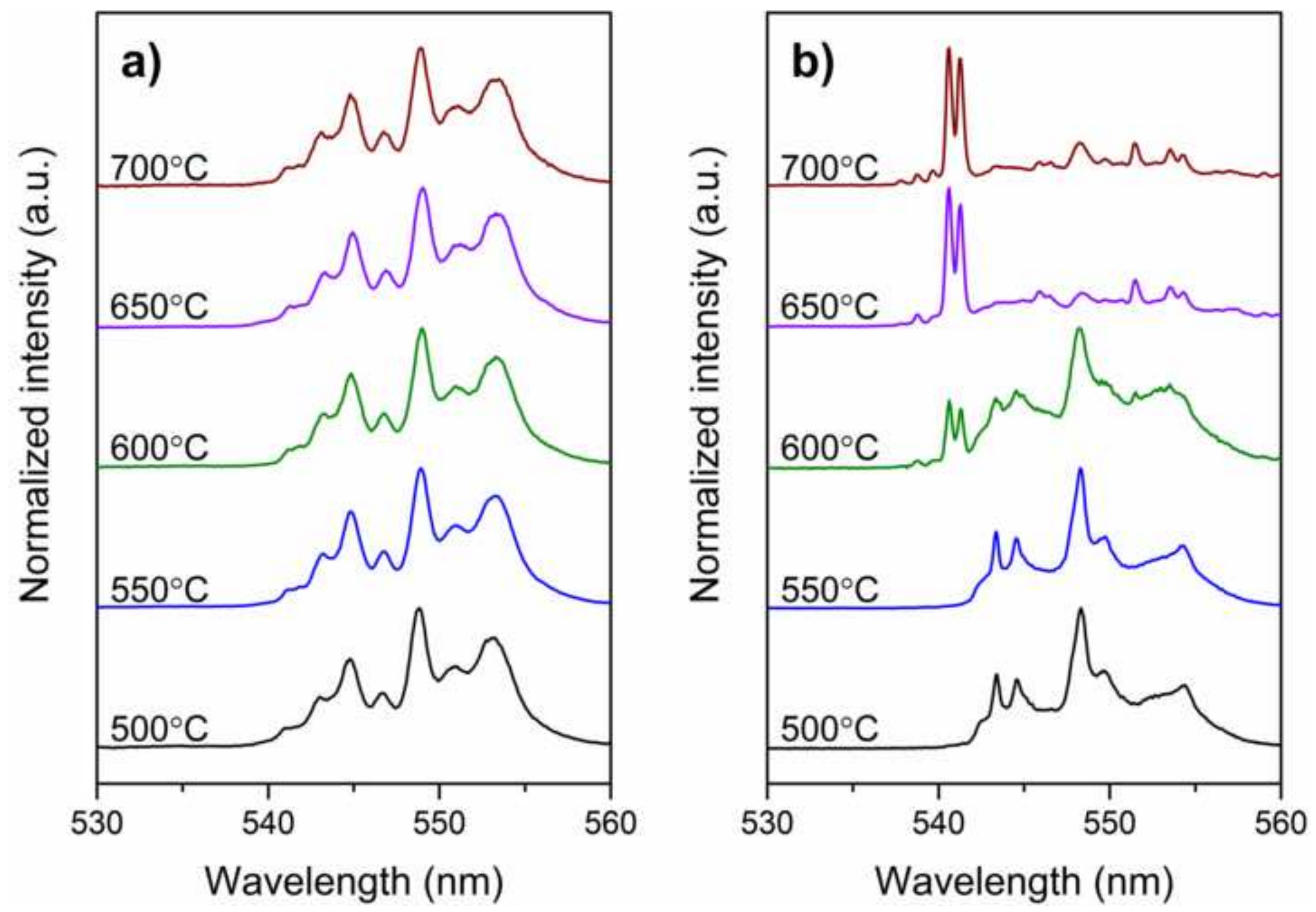

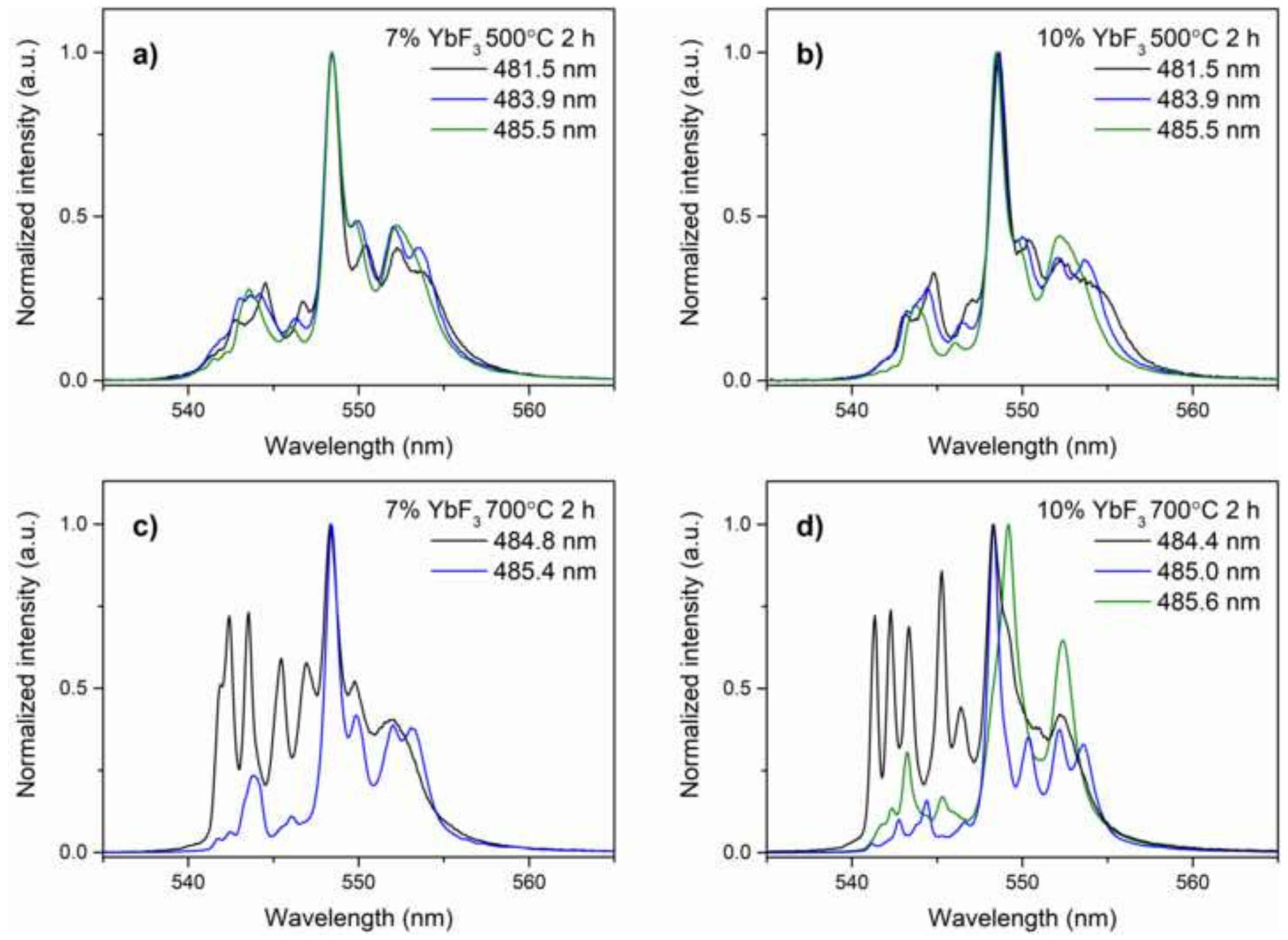
a)

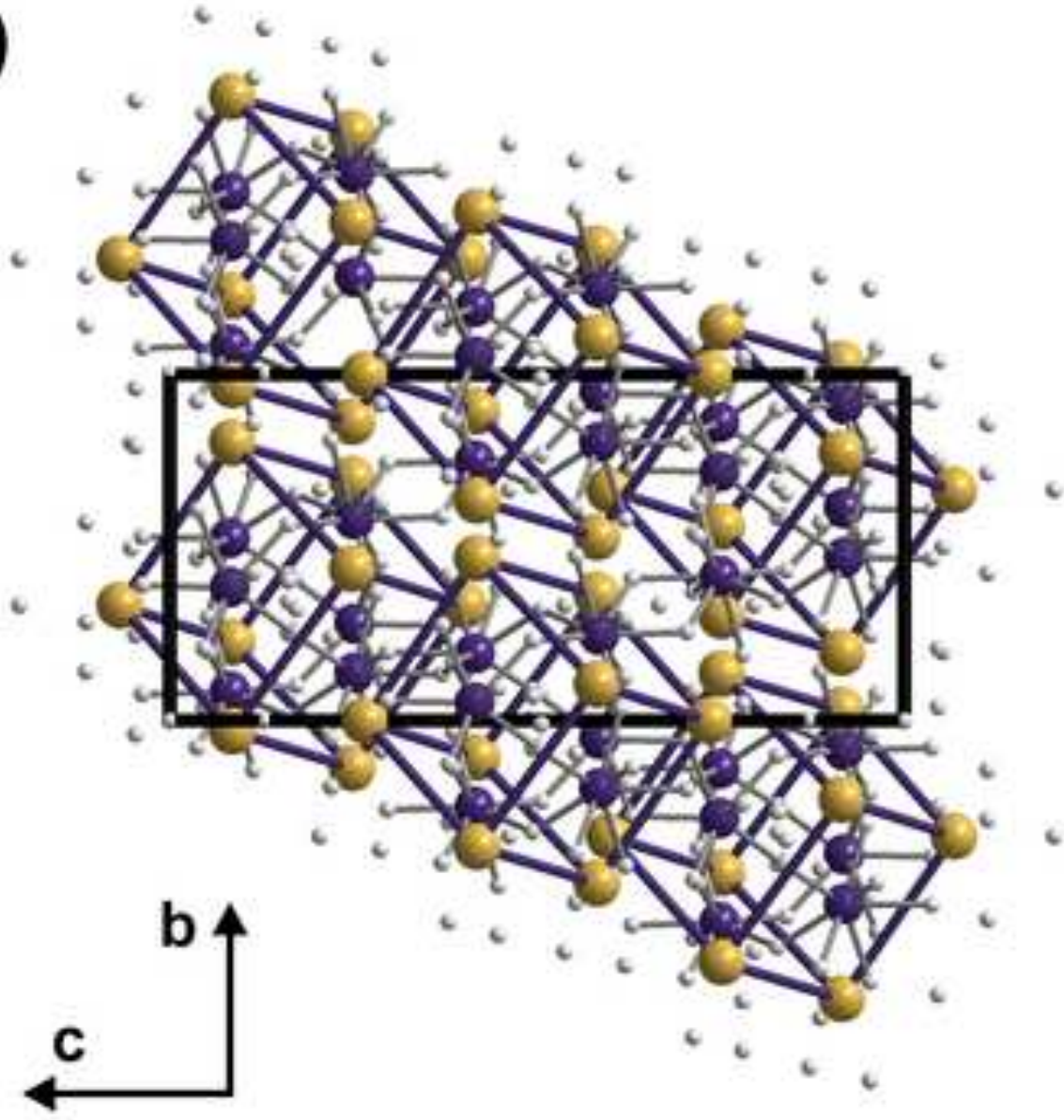

b)

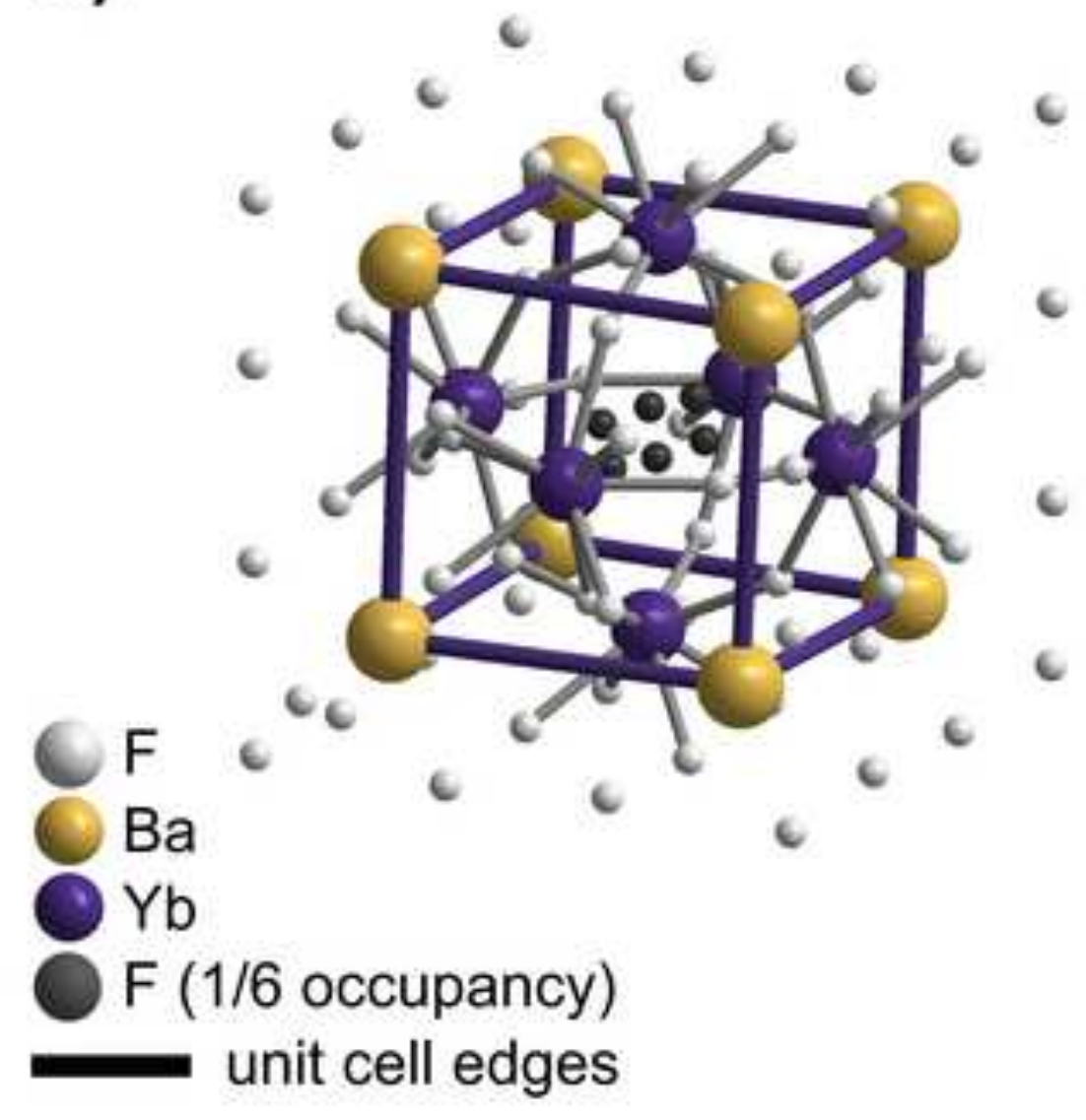



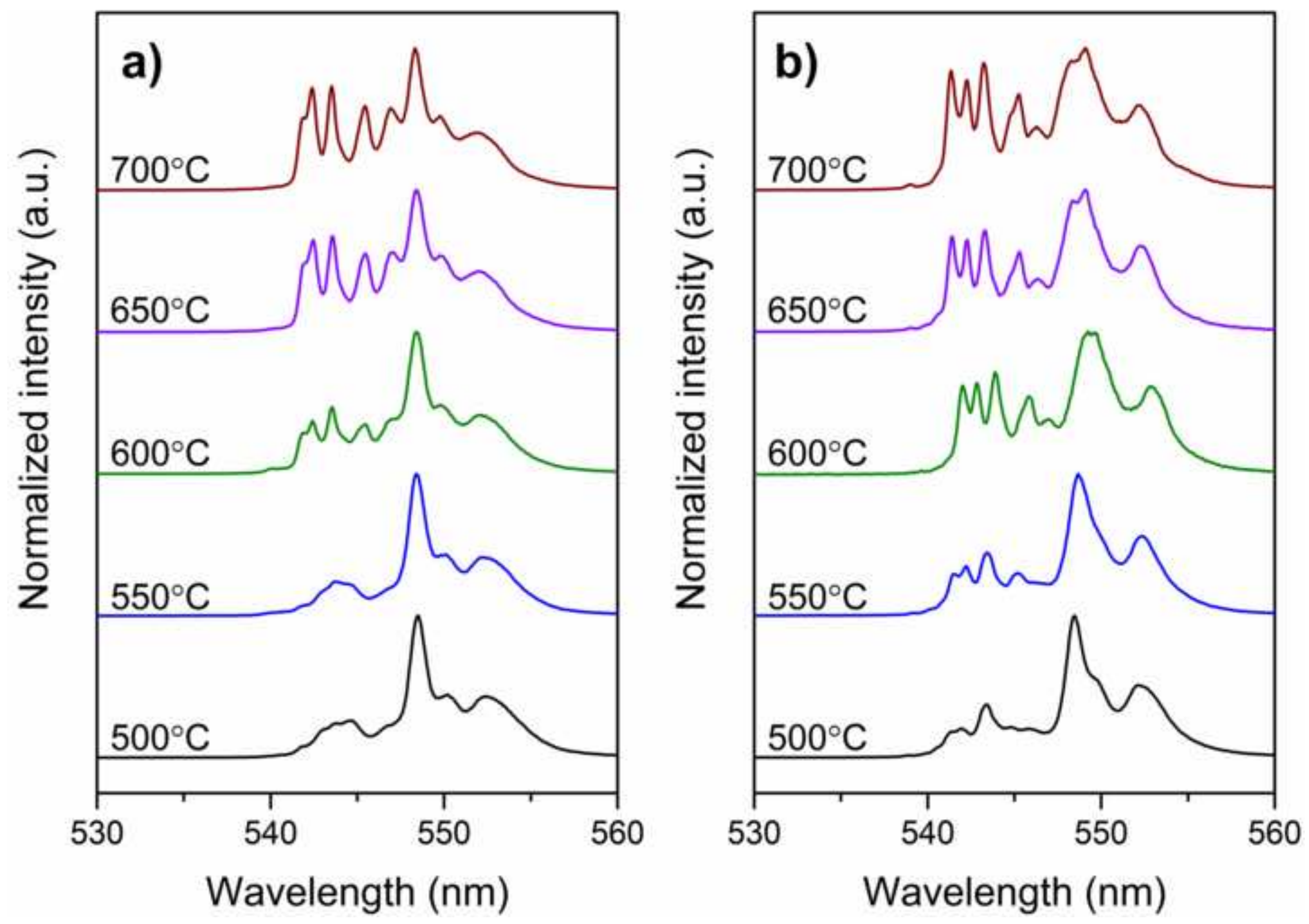
Fig. 1. DTA curves of the precursor glasses with $0,7,10$ and $14 \% \mathrm{YbF}_{3}$.

Fig. 2. XRD patterns of the glass ceramics heat treated at $650^{\circ} \mathrm{C}$ for $2 \mathrm{~h}$.

Fig. 3. XRD patterns of the precursor glass and glass ceramics with a) $7 \% \mathrm{YbF}_{3}$ (superstructure peaks are marked with o) and b) $10 \% \mathrm{YbF}_{3}$ (impurity phase is marked by *). Inset: the comparison of superstructure peaks of the glass ceramics and polycrystalline $\mathrm{Ba}_{4} \mathrm{Yb}_{3} \mathrm{~F}_{17}$.

Fig. 4. SEM micrographs of the glass ceramics with a) $0 \%$, b) $7 \%$, c) $10 \%$, and d) $14 \% \mathrm{YbF}_{3}$ heat treated at $700^{\circ} \mathrm{C}$ for $2 \mathrm{~h}$.

Fig. 5. UCL spectra of the glass ceramics with 7, 10 and $14 \% \mathrm{YbF}_{3}$ heat treated at $650^{\circ} \mathrm{C}$ for $2 \mathrm{~h}$ under $973 \mathrm{~nm}$ excitation. Inset: power dependence of UCL intensity of ${ }^{4} \mathrm{~F}_{9 / 2} \rightarrow{ }^{4} \mathrm{I}_{15 / 2}$ (red) and ${ }^{4} \mathrm{~S}_{3 / 2} \rightarrow{ }^{4} \mathrm{I}_{15 / 2}$ (green) emission in the glass ceramics with $7 \% \mathrm{YbF}_{3}$.

Fig. 6. a) Photoluminescence excitation spectra for ${ }^{4} \mathrm{~S}_{3 / 2} \rightarrow{ }^{4} \mathrm{I}_{15 / 2}$ (green) and ${ }^{4} \mathrm{~F}_{9 / 2} \rightarrow{ }^{4} \mathrm{I}_{15 / 2}$ (red) emission and b) luminescence decay of ${ }^{4} \mathrm{~F}_{9 / 2} \rightarrow{ }^{4} \mathrm{I}_{15 / 2}$ emission excited at 364,486 and $645 \mathrm{~nm}$ of the glass ceramics with $7 \% \mathrm{YbF}_{3}$ heat treated at $650^{\circ} \mathrm{C}$ for $2 \mathrm{~h}$.

Fig. 7. Partial energy level scheme of $\mathrm{Er}^{3+}$ and $\mathrm{Yb}^{3+}$ ions with possible UCL and crossrelaxation mechanisms.

Fig. 8. Luminescence spectra (exciting ${ }^{4} \mathrm{~F}_{7 / 2}$, monitoring ${ }^{4} \mathrm{~S}_{3 / 2} \rightarrow{ }^{4} \mathrm{I}_{15 / 2}$ emission) of $\mathrm{Er}^{3+}$ ions in the glass ceramics with a) $14 \% \mathrm{YbF}_{3}$ and b) $0 \% \mathrm{YbF}_{3}$ heat treated at $650^{\circ} \mathrm{C}$ for $2 \mathrm{~h}$. The luminescence spectra are detected at $10 \mathrm{~K}$.

Fig. 9. Luminescence spectra of $\mathrm{Er}^{3+}$ ions in the glass ceramics with a) $14 \% \mathrm{YbF}_{3}$ (excited at $483.0 \mathrm{~nm}$ ) and $0 \% \mathrm{YbF}_{3}$ (exited at $485.2 \mathrm{~nm}$ ) detected at $10 \mathrm{~K}$.

Fig. 10. Luminescence spectra (exciting ${ }^{4} \mathrm{~F}_{7 / 2}$, monitoring ${ }^{4} \mathrm{~S}_{3 / 2} \rightarrow{ }^{4} \mathrm{I}_{15 / 2}$ emission) of $\mathrm{Er}^{3+}$ ions in the glass ceramics with a,c) $7 \% \mathrm{YbF}_{3}$ and b,d) $10 \% \mathrm{YbF}_{3}$ heat treated at a-b) $500^{\circ} \mathrm{C}$ and $\mathrm{c}-\mathrm{d}$ ) $650^{\circ} \mathrm{C}$ for $2 \mathrm{~h}$. The luminescence spectra are detected at $10 \mathrm{~K}$.

Fig. 11. a) Crystal structure of the rhombohedral $\mathrm{Ba}_{4} \mathrm{Yb}_{3} \mathrm{~F}_{17}$, projection along a axis and $\mathrm{b}$ ) $\mathrm{Ba}_{8} \mathrm{Yb}_{6} \mathrm{~F}_{68}$ structural unit. Atomic positions taken from [59]. 
Fig. 12 Luminescence spectra of $\mathrm{Er}^{3+}$ ions in the glass ceramics with a) $7 \% \mathrm{YbF}_{3}$ (excited at $484.8 \mathrm{~nm}$ ) and $10 \% \mathrm{YbF}_{3}$ (exited at $484.4 \mathrm{~nm}$ ) detected at $10 \mathrm{~K}$.

Institute of Solid State Physics, University of Latvia as the Center of Excellence has received funding from the European Union's Horizon 2020 Framework Programme H2020-WIDESPREAD-01-2016-2017-TeamingPhase2 under grant agreement No. 739508, project CAMART² 